\title{
G band atmospheric radars: new frontiers in cloud physics
}

\author{
A. Battaglia ${ }^{1}$, C. D. Westbrook ${ }^{2}$, S. Kneifel ${ }^{3}$, P. Kollias ${ }^{3}$, N. Humpage ${ }^{1}$, U. Löhnert ${ }^{4}$, J. Tyynelä ${ }^{5}$, and G. W. Petty \\ ${ }^{1}$ Department of Physics and Astronomy, University of Leicester, University Road, Leicester, UK \\ ${ }^{2}$ Department of Meteorology, University of Reading, Reading, UK \\ ${ }^{3}$ McGill University, Montreal, Canada \\ ${ }^{4}$ Institut für Geophysik und Meteorologie, University of Cologne, Cologne, Germany \\ ${ }^{5}$ Department of Physics, University of Helsinki, Helsinki, Finland \\ ${ }^{6}$ University of Wisconsin-Madison, Madison, Wisconsin, USA
}

Correspondence to: A. Battaglia (a.battaglia@le.ac.uk)

Received: 20 September 2013 - Published in Atmos. Meas. Tech. Discuss.: 17 January 2014

Revised: 4 April 2014 - Accepted: 26 April 2014 - Published: 2 June 2014

\begin{abstract}
Clouds and associated precipitation are the largest source of uncertainty in current weather and future climate simulations. Observations of the microphysical, dynamical and radiative processes that act at cloud scales are needed to improve our understanding of clouds. The rapid expansion of ground-based super-sites and the availability of continuous profiling and scanning multi-frequency radar observations at 35 and $94 \mathrm{GHz}$ have significantly improved our ability to probe the internal structure of clouds in high temporal-spatial resolution, and to retrieve quantitative cloud and precipitation properties. However, there are still gaps in our ability to probe clouds due to large uncertainties in the retrievals.

The present work discusses the potential of $\mathrm{G}$ band (frequency between 110 and $300 \mathrm{GHz}$ ) Doppler radars in combination with lower frequencies to further improve the retrievals of microphysical properties. Our results show that, thanks to a larger dynamic range in dual-wavelength reflectivity, dual-wavelength attenuation and dual-wavelength Doppler velocity (with respect to a Rayleigh reference), the inclusion of frequencies in the $\mathrm{G}$ band can significantly improve current profiling capabilities in three key areas: boundary layer clouds, cirrus and mid-level ice clouds, and precipitating snow.
\end{abstract}

\section{Introduction}

Clouds are very complex, ubiquitous components of our atmosphere. Their complexity derives from their varied composition (water droplets and/or ice crystals with sizes in the order of microns to millimetres), and from their relationships both with very fine-scale convection and turbulence processes and with meso/synoptic-scale dynamical systems. Clouds have a profound impact on the Earth's climate. They exert a substantial influence on the Earth's radiation budget, efficiently reflecting sunlight into space (short-wave cooling) while they absorb infrared radiation emitted from the surface/lower atmosphere at lower temperatures (long-wave warming). The cloud radiative effect is very sensitive to the cloud microphysical and macrophysical structure, both in its long-wave and in its short-wave component. Small changes in cloud properties or coverage in a future climate can partially offset or substantially amplify the warming associated with a doubling of $\mathrm{CO}_{2}$ ("climate sensitivity"). Clouds also influence the atmospheric energy budget through the transport and release of latent heat. Due to the complex relations of these processes, cloud feedbacks remain the largest source of uncertainty in climate sensitivity estimates (Solomon et al., 2007), and due to the complex nature of the climate system they are the most difficult to disentangle (Stevens and Feingold, 2009). The blueprint for progress in improving representation of cloud processes in global climate (GCM) and numerical weather prediction (NWP) models must follow a demanding path that involves an orchestrated combination of models, essential tools for diagnosing processes and quantifying feedbacks, and observations, which test the model's credibility in representing these processes. One of the current weaknesses of GCMs and NWP models lies in the embedded cloud parameterizations with levels of empiricism and assumptions that are hard to evaluate with current 
global observations (Stephens, 2005). In order to break the cloud parameterization deadlock, the road map to progress can fork in two directions: from one side GCM and NWP models are moving towards resolutions fine enough to represent individual cloud elements, and from the other side new cutting-edge observational techniques for improving quantitative cloud microphysical retrievals must be explored. This work takes the second path and explores the potential advantages for cloud physics studies of using the G band (110$300 \mathrm{GHz}$ ), which lies within the extremely high frequency (EHF, 30-300 GHz) band as defined by the Institute of Electrical and Electronics Engineers (IEEE, 2003). The G band lies just above the $\mathrm{W}$ band $(75-110 \mathrm{GHz})$ and bridges the gap with the far infrared (above $300 \mathrm{GHz}$ ). Specifically, two "window" frequencies within the G band will be considered (140 and $220 \mathrm{GHz}$ ). Given that the total scattering and absorption by a cloud volume varies smoothly with frequency, these two frequencies will epitomize the behaviour within the whole band.

Cloud radars at $35 \mathrm{GHz}$ and $94 \mathrm{GHz}$ are routinely operated from the ground (e.g. within the CloudNet and the US ARM (Atmospheric Radiation Measurement) Program, Illingworth et al., 2007; Ackerman and Stokes, 2003; Mather and Voyles, 2013) and from a variety of ship-based and airborne platforms (Kollias et al., 2007). In space, the CloudSat $94 \mathrm{GHz}$ cloud profiling radar has been operating since May 2006 (Stephens et al., 2008). Combined with other NASA A-Train constellation sensor data, CloudSat observations offer unique, global views of the vertical structure of clouds and precipitation in tandem, thus bridging a gap in the measurement of the Earth's hydrological cycle (Berg et al., 2010). They also provide valuable estimates of global ice water paths (Delanoë and Hogan, 2010), global snow cloud characteristics (Liu, 2008b), and add new insight into tropical penetrating convection and marine boundary layer clouds (Stephens et al., 2008).

A further technological and scientific leap forward will be provided by the upcoming ESA Earth, Clouds, Aerosols, and Radiation Explorer (EarthCARE) mission, that will deploy a $94 \mathrm{GHz}$ radar, the first ever in space with Doppler capabilities. The variety of these research activities clearly demonstrates the impressive progress made in recent years in mm-wave radar technology, specifically in highefficiency antenna assembly, low-loss quasi-optical transmission line, high-power amplifiers and low-noise-figure receivers (Tanelli et al., 2008). However, to date, $94 \mathrm{GHz}$ radar remains the highest frequency radar routinely used for cloud remote sensing. There have only been a few examples of cloud radars operating at $140-215 \mathrm{GHz}$ in the past (Nemarich et al., 1988; Mead et al., 1989; Wallace, 1988). Such instruments used an extended interaction klystron (EIK), operated as a free running oscillator. The sensitivity was limited as this approach necessitated short pulses, incoherent operation without Doppler and wide receiver bandwidths to accommodate frequency drift. Since the early work of
Nemarich et al. (1988); Mead et al. (1989); Wallace (1988) and Lhermitte (1990) there has been little discussion in the last 20 years on the advantages of radars operating at $\mathrm{G}$ band. Today, several of the technological challenges that made the development of radar in $\mathrm{G}$ band in the past a risky proposition are now removed thanks to technological breakthroughs (Durden et al., 2011). Thus, it is timely to revisit the topic of the potential applications of $\mathrm{G}$ band radars in cloud research. Here, we state their added value in cloud research when operated in ground-based super-sites complementing existing cloud radar facilities. $G$ band radars could be potentially useful also from space and indeed they have been already proposed for characterizing cirrus clouds (Hogan and Illingworth, 1999). However most of the applications proposed in this work require Doppler spectra. In low-Earth-orbit satellites the fast satellite motion produces a large Doppler fading which strongly reduces the potential of using multifrequency Doppler spectra techniques (Battaglia et al., 2013, and references therein). The added value of $G$ band radars is discussed in the context of our current understanding of cloud research and the identification of existing gaps and limitations in quantitative cloud retrievals.

The paper is organized as follows: Sect. 2 describes gaps in cloud and precipitation profiling observational capabilities in three key areas of relevance for cloud-related studies. Section 3 provides a background on the current state of the art for millimetre radar profiling along with the scattering and absorption characteristics which can be expected at higher frequencies, while Sect. 4 discusses potential multiwavelength retrieval approaches which use $\mathrm{G}$ band radars, in relation to the three cloud themes discussed in Sect. 2. In Sect. 5 we present a recommended technical specification for a $220 \mathrm{GHz}$ ground-based radar system to achieve the science objectives described in this paper. Conclusions and recommendations for future works are discussed in Sect. 6.

\section{Gaps in cloud profiling observational capabilities}

The few radars operated in the $G$ band in the past provided observations of fog and low level clouds (Mead et al., 1989; Wallace, 1988) and of falling snow and rain (Nemarich et al., 1988; Wallace, 1988). On the other hand, Hogan and Illingworth (1999) explored the potential of a $215 \mathrm{GHz}$ channel in a dual-frequency space-borne radar to size cirrus clouds and profile ice water contents. Driven by these first observations and notional studies and by the initial assessment of the applicability of millimetre Doppler radars for cloud studies provided by Lhermitte (1990), hereafter we focus on three cloud research areas where radars operated in the $\mathrm{G}$ band are expected to provide additional information: (1) boundary layer (BL) clouds; (2) cirrus and mid-level ice clouds; (3) precipitating snow. These cloud types play a critical role for NWP and in GCMs. For instance, because of their large horizontal coverage and their 
high albedo, BL clouds such as stratus and stratocumulus are the largest contributor to uncertainty in future climate predictions, with large discrepancies in the amount of sunlight being reflected by the simulated clouds (Bony and Dufresne, 2005). BL cloud persistence strongly affects day-time surface heating and night-time long-wave cooling; hence, errors in their representation lead to incorrect forecasting of fog, ice, and other hazardous conditions. Though drizzle formation is key to the maintenance and dissipation of the low-stratiform clouds (Wood, 2012) there are still significant differences in the drizzle amount in models and observations, with an over-prediction of drizzle from BL clouds in cloud modelling (Stephens et al., 2010). Thin, low-level liquid clouds are also key in affecting surface radiative fluxes in polar areas (e.g. Bennartz et al., 2013). Similarly ice water content of cirrus in GCMs is not well simulated at present. Global average ice water path varies by more than order of magnitude ( 0.01 and $0.2 \mathrm{~kg} \mathrm{~m}^{-2}$ ) between different climate models (Solomon et al., 2007). Unfortunately, a similar spread also exists amongst satellite estimates (Eliasson et al., 2011), which makes it difficult to make progress. Measuring snowfall, an important component of the water cycle (Mugnai et al., 2005), is an even more complicated matter because of the enormous complexity of snow crystal habit, density, and particle size distribution.

Thus, in order to significantly improve the representation of the aforementioned cloud types in climate and NWP models, novel remote sensing techniques capable of characterizing their micro- and macro-physical properties (which are the drivers of their radiative properties) are certainly needed. Hereafter we review the current state of the art in the radarbased remote sensing of these cloud systems and identify critical measurement gaps and limitations.

\subsection{Boundary layer clouds}

While remote sensing of the column integrated amount of cloud liquid water (LWP) using passive microwave radiometry can be achieved with sufficient accuracy (Crewell and Löhnert, 2003; van Meijgaard and Crewell, 2005), only limited information can be extracted on the vertical profile using the cloud radar backscatter signal. This is mainly because the liquid water content (LWC, proportional to the third moment of the droplet spectrum) of BL clouds is dominated by small (diameter $<40 \mu \mathrm{m}$ ) cloud droplets, whereas the radar backscatter signal ( $Z$, proportional to the sixth moment of the droplet spectrum) is dominated by drizzle when present (Fox and Illingworth, 1997). Nevertheless, several retrieval techniques have been developed that use millimetre radar-only measurements or combine radar with microwave radiometer measurements (Atlas, 1954; Frisch et al., 1998, 2002; Williams and Vivekanandan, 2007; Brandau et al., 2010; Ellis and Vivekanandan, 2011) to retrieve LWC and/or cloud effective radius. Most of these retrievals assume monomodal size distributions, which are usually described through a log-normal or a modified gamma distribution. If the (typically) three parameters of the size distribution are to be derived from height-resolved $Z$ and integrated LWP measurements, this usually requires certain prior assumptions, i.e. concerning the width and the total number concentration of the size distribution. Generally, the performance of these methods degrades when precipitation develops and the size distribution becomes multi-modal. Löhnert et al. (2008) developed the variational integrated profiling technique (IPT) for LWC profiles from a combination of cloud radar and microwave radiometer relying on the target classification provided by Cloudnet (www.cloud-net.org), which can deliver automated information on whether or not the cloud is precipitating. The IPT then applies different $Z$-LWC relationships depending on the precipitation conditions in the cloud, though LWC uncertainties can nevertheless be larger $50 \%$ and the retrieval of cloud droplet size is not possible in the presence of precipitation. Hogan et al. (2005) proposed the use of dual-wavelength reflectivity (DWR) methods to profile liquid water clouds. In this case the accuracy is limited by the relatively small amount of dual-wavelength attenuation obtained when using frequencies at 35 and $94 \mathrm{GHz}$ (the differential mass attenuation coefficient is roughly $4 \mathrm{~dB} \mathrm{~km}^{-1}$ per $\mathrm{g} \mathrm{m}^{-3}$ ), which can be difficult to measure and usually requires significant averaging. Retrieval of drizzle properties below cloud base is also challenging: O'Connor et al. (2005) demonstrated a radar-lidar method to profile the drizzle drop spectrum below cloud base. Likewise Westbrook et al. (2010) demonstrated a two-frequency lidar method. However, the main drawback of these methods is that they cannot profile the drizzle inside the cloud, nor can they function if the drizzle is obscured by an intervening layer of cloud. In a recent study, Kollias et al. (2011) proposed using higher moments of cloud radar Doppler spectra (e.g. skewness and kurtosis in addition to reflectivity, velocity and spectral width) for constraining microphysical retrievals within clouds. They derived relationships between radar Doppler moments and stratocumulus dynamics and microphysics valid for cloud-only, cloud mixed with drizzle, and drizzle-only particles in the radar sampling volume.

\subsection{Cirrus and mid-level ice clouds}

A variety of algorithms that utilize ground-based and spacebased active remote sensing have been proposed for the retrieval of ice cloud microphysical properties. Most of the proposed algorithms can be classified as radar-only (e.g. Benedetti et al., 2003; Austin et al., 2009), radar-lidar (e.g. Donovan and van Lammeren, 2001; Wang and Sassen, 2002; Okamoto et al., 2003; Delanoë and Hogan, 2008, 2010) and radar Doppler based techniques (e.g. Matrosov et al., 2002; Mace et al., 2002; Delanoë et al., 2007; Szyrmer et al., 2012). Another approach is to use cloud radar observations at two or more frequencies, such that one of the radars has a wavelength comparable to the size of the ice particles. 
Such measurements have been made at 35 and $94 \mathrm{GHz}$, and have been used by Hogan et al. (2000); Wang et al. (2005); Westbrook et al. (2006); Matrosov (2011) to estimate particle size in ice clouds. However, size information is limited to clouds containing rather large particles, several hundred microns in size. If $\mathrm{G}$ band measurements are included, it should be possible to size much smaller particles (Matrosov, 1993; Tang and Aydin, 1995; Hogan and Illingworth, 1999). This is explored in more detail in Sect. 4.2.

Another application which makes $\mathrm{G}$ band radars particularly appealing, when complemented by proper in situ measurements and particle models, is the verification of ice particle scattering models. Scattering properties of ice particles are now consistently inferred over the electromagnetic spectrum from the ultraviolet through to the far-infrared, whose lower boundary is conventionally assumed at $300 \mathrm{GHz}$ (Yang et al., 2013). Scattering libraries complementary to these are available in the microwave regime (Kim et al., 2007; Hong, 2007b; Liu, 2008a). Because of the vicinity to the far-IR region, measurements above $94 \mathrm{GHz}$ could bridge the gap between microwave and far-IR electromagnetic scattering models.

\subsection{Precipitating snow}

At present most global snow algorithms remain empirical in nature, though there has been considerable progress towards physical approaches, particularly using radar technology. CloudSat (Stephens et al., 2008) offers one of the most sophisticated possibilities for deriving the distribution of global snowfall (Liu, 2008b). The advantage of CloudSat's cloud profiling radar is that one can derive information on the vertical distribution of snow as well as small cloud ice particles and thus estimate the surface snowfall rate even during relatively light precipitation cases (Liu, 2008b; Matrosov et al., 2008; Kulie and Bennartz, 2009). However, radar-based algorithms rely on statistical relations between the equivalent radar reflectivity factor $Z_{\mathrm{e}}$ and snowfall rate $S$, which are in turn a function of particle fall velocity, particle habit (Petty and Huang, 2010; Kulie et al., 2010) and particle size distribution (PSD). The large natural variability of such properties can lead to uncertainties greater than $100 \%$ in snowfall estimates (Hiley et al., 2011). This poses a microphysical deadlock.

The complexity of snow profiling calls for an integrated approach of multi-frequency instruments. In this context lidar and radar can provide useful complementary and synergetic information (Battaglia and Delanöe, 2013, and references therein). By combining multi-frequency measurements from active and passive microwave remote sensing instruments, essential assumptions on particle type and size distribution have been evaluated through consistency checks with radiative transfer modelling in snow clouds (Löhnert et al., 2011; Kneifel et al., 2010; Kulie et al., 2010). These assumptions can be constrained further by in situ measurements and continuous temperature and humidity profile information. Dual-wavelength radar techniques have also been adopted both for ground-based observations (Matrosov, 1998) and proposed for space-borne configuration (e.g. for the ESA EE8 Polar Precipitation Missions, Joe et al., 2010), based on the idea that dual-wavelength reflectivities can be used to derive characteristic size parameters of the snow PSD like mass median diameters and to partly mitigate the microphysical deadlock. It is known however, that even adopting $\mathrm{W}$ band as the higher frequency, the non-Rayleigh scattering effects come into play only at a relatively large particle size (Kneifel et al., 2011). When $\mathrm{G}$ band frequencies are used, dual/triple wavelength radar approaches can potentially be more effective for medium to light snowfall rate regimes (see Sect. 4.3 for specific examples).

\section{Radar scattering properties at millimetre wavelengths}

During the past two decades millimetre-wavelength cloud radars have emerged as central pillars in evaluating cloud representation in GCM and NWP models (Illingworth et al., 2007). Millimetre radars are particularly attractive and effective because of their inherent compactness and portability, their high sensitivity and minimal susceptibility to Bragg scattering and ground clutter (Kollias et al., 2007). In the Rayleigh scattering regime the radar reflectivity factor $Z$ is independent of radar wavelength while the radar backscattering cross section, proportional to $\lambda^{-4}$, is much greater at shorter wavelengths. Thus, millimetre-wavelength radars are capable of supplementing the dynamic range of centimetrewavelength radars with the capability of observing shallow cumuli and other cloud types well before they develop precipitation, without the use of high-power transmitters and large antennas.

\subsection{Gas attenuation}

The large sensitivity at shorter wavelengths comes at the price of strong absorption by atmospheric gases and by hydrometeors (Lhermitte, 1990; Kollias et al., 2007). For the EHF range, atmospheric windows (minima in the attenuation spectrum) are located at approximately $35 \mathrm{GHz}\left(\mathrm{K}_{\mathrm{a}}\right)$, $94 \mathrm{GHz}(\mathrm{W}), 140 \mathrm{GHz}(\mathrm{G}), 215 \mathrm{GHz}(\mathrm{G})$ and $342 \mathrm{GHz}$ (see Fig. 1). Such atmospheric windows are used for radar operations and are separated by absorption lines: the $22.235 \mathrm{GHz}$ water vapour absorption line separates the $\mathrm{K}_{\mathrm{u}}$ and $\mathrm{K}_{\mathrm{a}}$ bands, whilst the $60 \mathrm{GHz}$ oxygen absorption band (57-64 GHz) separates the $\mathrm{K}_{\mathrm{a}}$ and $\mathrm{W}$ bands. The single absorption line of the oxygen molecule centred at $118.75 \mathrm{GHz}$ separates the $\mathrm{W}$ and $\mathrm{G}$ bands. Within the $\mathrm{G}$ band, attenuation is mainly driven by water vapour absorption, especially around the $183 \mathrm{GHz}$ absorption line that separates the 140 and $215 \mathrm{GHz}$ atmospheric windows. For instance, at the ground level water vapour 


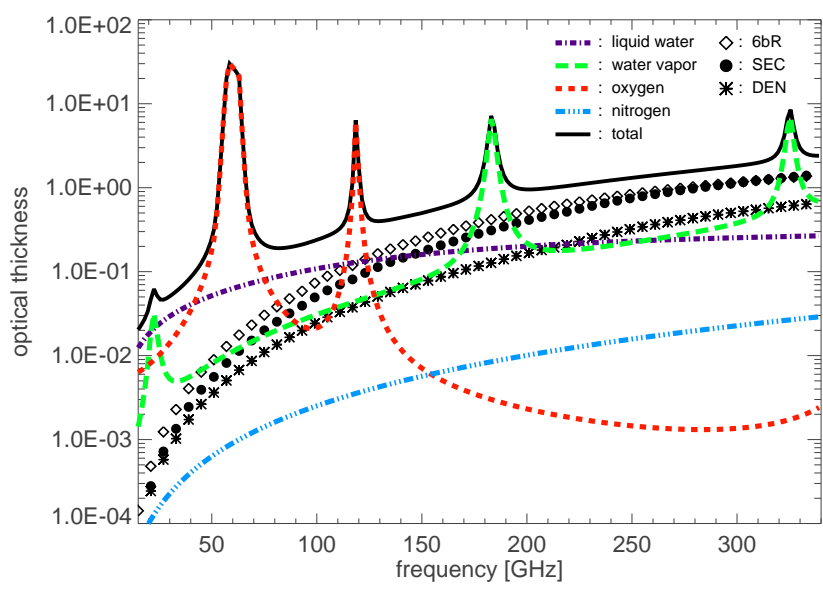

Figure 1. Optical thickness vs. frequency for an atmosphere with typical winter conditions at the Zugspitze site (2960 m altitude) including a single-layer cloud with homogeneously distributed $L W P=0.1 \mathrm{~kg} \mathrm{~m}^{-2}$ and $S W P=0.2 \mathrm{~kg} \mathrm{~m}^{-2}$. Different snow habits have been considered classified according to Liu (2008a): six-bullet rosettes (6bR), sector snowflake (SEC), dendrite snowflake (DEN).

attenuation can vary between $1 \mathrm{~dB} \mathrm{~km}^{-1}$ for cold, dry conditions to as much as $12 \mathrm{~dB} \mathrm{~km}^{-1}$ for hot, humid atmospheres. As a result, $G$ band is especially suited for operations in the polar regions and high latitude/altitude environments where atmospheric water vapour is scarce, or from satellite platforms for the analysis of ice particles in the drier upper troposphere.

\subsection{Hydrometeor attenuation}

Clouds and precipitation (particularly in the liquid phase) can produce severe attenuation for millimetre-waves. Radar attenuation (or extinction as referred in radiative transfer terminology) is caused by absorption and scattering of the transmitted radiation out of the radar beam direction, with the second component becoming increasingly important at higher frequencies. $1 \mathrm{~g} \mathrm{~m}^{-3}$ of liquid at $10^{\circ} \mathrm{C}$ distributed across a cloud droplet distribution with $D_{0}<50 \mu \mathrm{m}$ causes one-way attenuation of $0.8,4.1,7.2,12.0 \mathrm{~dB} \mathrm{~km}^{-1}$ at $35,94,140$ and $220 \mathrm{GHz}$, respectively (see Fig. 2, where the curves intercept the $y$ axis). These values are computed using the water refractive index provided by Ellison (2007), and are similar to those listed in Table 2 in Lhermitte (1990) which were computed using the older water refractive index model from Ray (1972). In the Rayleigh approximation the attenuation coefficient per unit mass is dominated by the absorption component; it is linearly proportional to the imaginary part of the dielectric factor, $K=\left(n^{2}-1\right) /\left(n^{2}+2\right)$ (where $n$ the ice complex refractive index), and inversely proportional to the wavelength (Lhermitte, 1990). Therefore, if the Rayleigh approximation is applicable then measuring attenuation is basically equivalent to determining the mass content, a key parameter for cloud modellers. For larger drop radii, $r$, both the absorption and scattering coefficients increase, reach a maximum greatly exceeding the Rayleigh absorption value where $r / \lambda \approx 1.5$, and then decrease slowly to the geometric optics limit (thus frequency independent). Note also the increasing contribution of scattering to attenuation with increasing raindrop radius (departure of continuous from dashed lines). The single-scattering albedo (not shown for brevity) quickly rises from zero to about 0.5 at the maximum position, before steadily increasing to values above 0.6 at large radii for all the frequencies considered here.

While attenuation of the radar signal by hydrometeors in the atmosphere can be seen as a drawback (e.g. potential complete attenuation of the radar signal in rain after a few kilometres) it can also be exploited to provide water content profiles by using dual-frequency approaches. Hogan et al. (2005) demonstrated water content profiling capabilities at a vertical resolution of $150 \mathrm{~m}$ for stratocumulus clouds with an accuracy of $0.04 \mathrm{~g} \mathrm{~m}^{-3}$ by employing the $35-94 \mathrm{GHz}$ (8.6-3.2 $\mathrm{mm}$ ) pair (when dwelling times longer than one minute are adopted). $G$ band frequencies have the advantage of producing even larger dual-wavelength attenuation, with the possibility of more accurate profiling and of targeting thinner boundary layer clouds. Qualitative observations of fog and stratocumulus clouds with a $215 \mathrm{GHz}$ system have been presented by Mead et al. (1989), who observed reflectivities under foggy conditions of around $-30 \mathrm{dBZ}$, but these were not quantitatively useful because of their inability to quantify attenuation of the beam without additional measurements. More than 25 years since the measurements reported by Mead et al. (1989), it is now time to provide a quantitative assessment of the value of $\mathrm{G}$ band radar measurements.

Even snow-bearing clouds produce significant attenuation at frequencies above $100 \mathrm{GHz}$ (Fig. 1). This has already been demonstrated by field measurements conducted by Wallace (1988) and by Nemarich et al. (1988) at 140 and $220 \mathrm{GHz}$, with attenuations as large as 3 to 5 (1.6 to 3.6) $\mathrm{dB} \mathrm{km}^{-1}$ per $\mathrm{g} \mathrm{m}^{-3}$ at $140 \mathrm{GHz}$ and 8.5 to 12.5 (6 to 11.3) $\mathrm{dB} \mathrm{km}^{-1}$ per $\mathrm{g} \mathrm{m}^{-3}$ at $220 \mathrm{GHz}$, respectively for Wallace (1988) (Nemarich et al., 1988). The frequent occurrence of supercooled liquid layers at temperatures higher than $-20^{\circ} \mathrm{C}$ (e.g. Battaglia and Delanöe, 2013), or the presence of melting snowflakes, can further enhance the amount of attenuation in ice/snow clouds.

From a theoretical point of view, owing to the complexity of ice crystal habit, the discrete dipole approximation (DDA, Draine and Flatau, 2000) is typically used to compute snow single-scattering properties at millimetre and sub-millimetre wavelengths, though different methodologies have been used in the past (e.g. the finite difference time domain, Tang and Aydin, 1995; Aydin and Walsh, 1999) and in more recent times (e.g. the generalized multi-particle Mie methods, Botta et al., 2010, 2011). An extensive review of electromagnetic scattering models is provided in Mishchenko et al. (2000). The availability of large computational power, needed especially if complex particles with large size parameter are 


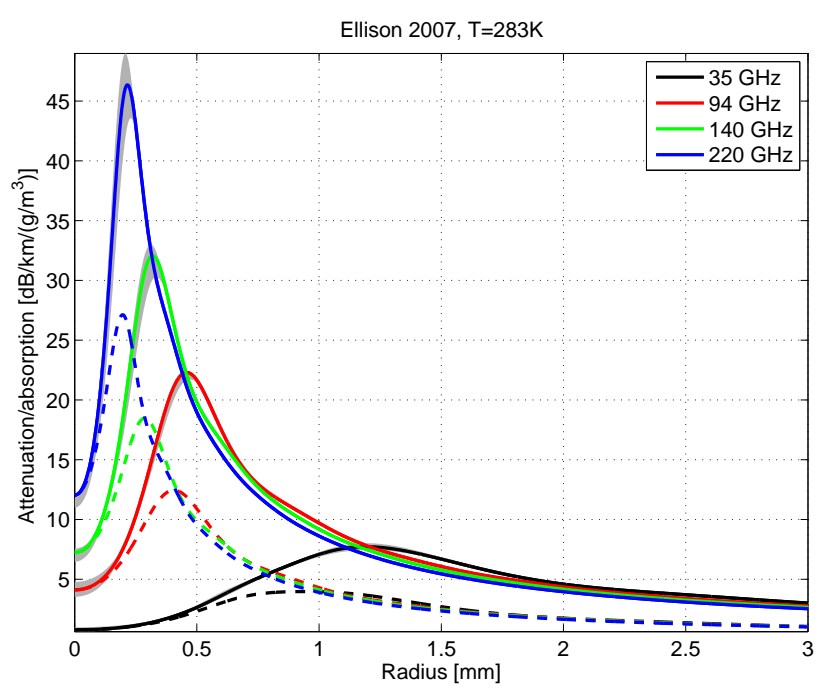

Figure 2. Mass absorption (dashed) and attenuation (continuous lines) coefficient as a function of particle radius for the four frequencies as indicated in the legend. The curves correspond to a water temperature of $10^{\circ} \mathrm{C}$ while the grey shadowing covers the variability associated with temperatures ranging between 0 and $20^{\circ} \mathrm{C}$. The model proposed by Ellison (2007) has been used to compute the water refractive index.

simulated, has recently made possible the creation of different data sets representative of both pristine particles (Liu, 2008a; Hong, 2007a; Kim, 2006) and very complex aggregate structures (Ishimoto, 2008; Petty and Huang, 2010; Tyynelä et al., 2013).

A selection of snow attenuation coefficients derived from such data sets are presented in Fig. 3. Their behaviour is completely different from that of water droplets depicted in Fig. 2. The small imaginary component of the ice refractive index at millimetre-wavelengths (Warren and Brandt, 2008) makes scattering the key mechanism for attenuation, even at small masses (compare the yellow and cyan lines in Fig. 3). As a consequence the simulated mass attenuation coefficients exhibit a large variability associated with habit type and are strongly increasing with ice crystal mass (by almost two orders of magnitude passing from small to extremely large ice crystals). Above $94 \mathrm{GHz}$, attenuation by (dry) snow is no longer negligible and can significantly affect the radar signal. Although at $94 \mathrm{GHz}$ attenuation of only a few dBs is expected in typical snow scenarios for vertical observations (Matrosov and Battaglia, 2009), at frequencies within the $\mathrm{G}$ band the attenuation coefficient rapidly increases with frequency. At $220 \mathrm{GHz}$, depending on size and shape, snowflakes are extinguishing radiation by a factor of 5 to 25 more than at $94 \mathrm{GHz}$ (bottom panel in Fig. 3). Similar plots but for lower frequencies are presented in Petty and Huang (2010). Aggregates of rosettes and hexagonal columns, as well as single-crystal bullet rosettes and sector snowflakes, produce more attenuation compared to spheroids
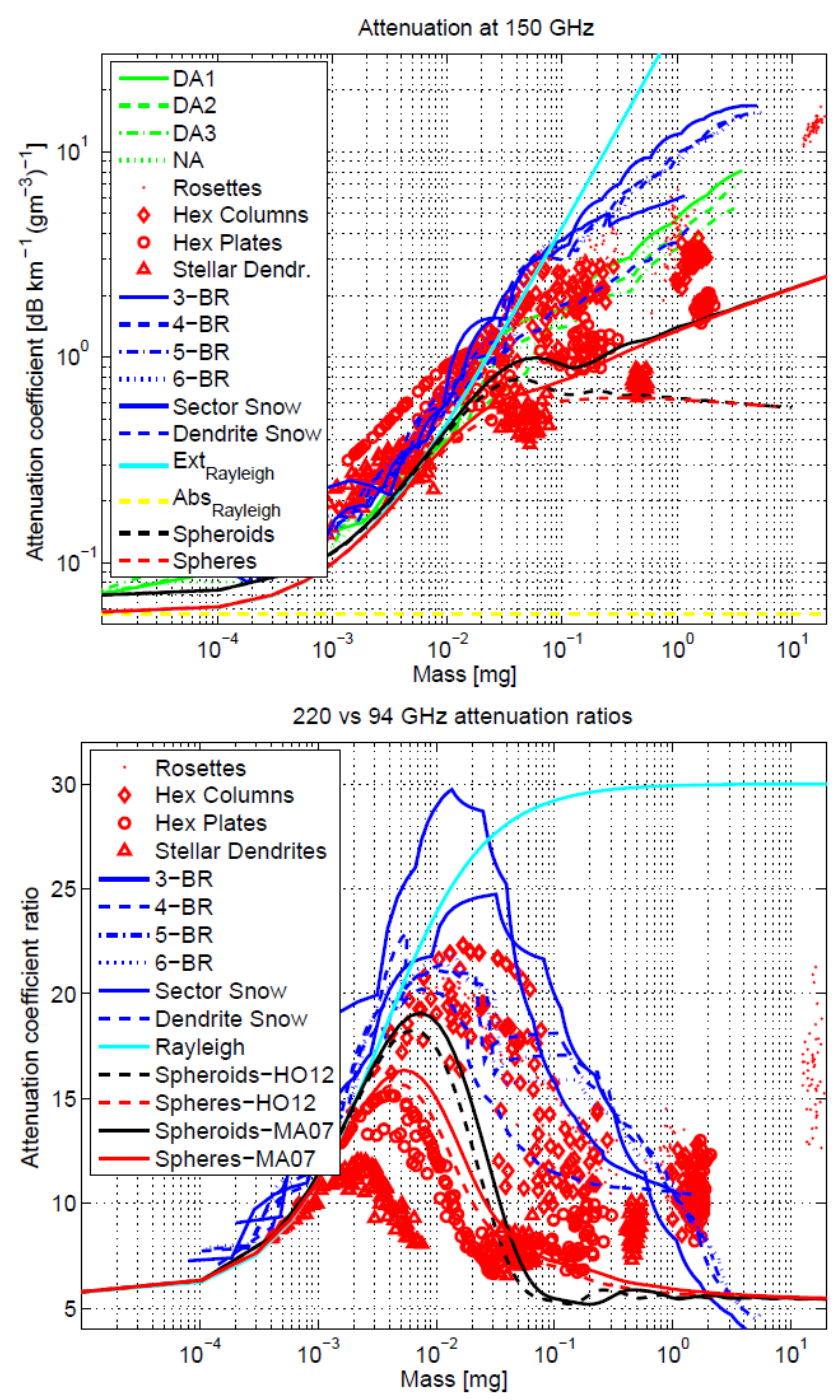

Figure 3. Top panel: one-way mass snow attenuation coefficient as a function of ice crystal mass for different habits as indicated in the legend for $150 \mathrm{GHz}$ (top). Bottom panel: ratio between 220 and $94 \mathrm{GHz}$ attenuation coefficients. Green lines: Petty aggregate snowflakes (Petty and Huang, 2010); red symbols: Tyynelä aggregate snowflakes (Tyynelä et al., 2013); blue lines: Liu single ice particles (Liu, 2008a).

or aggregates of stellar dendrites which are found to be less efficient scatterers. For particles heavier than $0.1 \mathrm{mg}$, shape variability can account for almost an order of magnitude in variability of the attenuation coefficient both at 150 and $220 \mathrm{GHz}$, an important signature for distinguishing different habits. A proper validation of these attenuation coefficients is also of crucial importance for the ice/snow passive microwave remote sensing techniques that make use of frequency channels within the G band (Buehler et al., 2012; Grecu and Olson, 2008; Skofronick-Jackson et al., 2004). 


\subsection{Mie and non-spherical backscattering effects}

The Rayleigh scattering approximation is valid as long as the particle size is much smaller than the wavelength (Bohren and Huffman, 1983). When this approximation is no longer valid (usually referred to as the "Mie regime") backscattering cross sections do not monotonically increase with the sixth power of the particle diameter, rather they exhibit an oscillatory behaviour with minima and maxima corresponding to resonant sizes (Kollias et al., 2002). Lhermitte (1990) provides a comprehensive review of radar reflectivity, Doppler spectra and absorption coefficients for ice and water spherical particles in the millimetre-wavelength domain. In the case of rain, for PSD including larger particles, there is a decrease in the radar reflectivities and in the mean Doppler velocities at $\mathrm{G}$ band frequencies compared to the Rayleigh reference values. For instance, a $2 \mathrm{~mm} \mathrm{~h}^{-1}$ rain distributed according to a Marshall and Palmer PSD produces reflectivities of 30 , $20,12.5$ and $4 \mathrm{dBZ}$ at $35,94,140$ and $220 \mathrm{GHz}$, respectively.

Dealing with ice particles is more challenging due to their non-spherical shapes. The fine structure of ice particles is not affecting the scattering properties as long as the wavelength is large compared to the geometric size of the structures. However, millimetre radars become increasingly sensitive to these fine-scale structures with increasing frequency. Thus, the "classical" approximation of ice particles by spheres leads to erroneous scattering intensities at millimetre wavelengths: the solid-sphere approximation (i.e. sphere with the same mass but density of pure ice) results in scattering which is too strong, while the soft-sphere approximation (i.e. sphere with the same mass and size but with the density of an ice/air mixture) causes the scattering intensity to be too weak (Liu, 2008a; Johnson et al., 2012).

However, for the vast majority of ice crystal applications, simple approximations are still used at 35 and $94 \mathrm{GHz}$. Hogan et al. (2012) suggests that ice particles can be adequately treated as horizontally aligned spheroids with an axial ratio of 0.6 and with a mass-diameter relationship as provided by Brown and Francis (1995). These conclusions apply to ice crystals and snowflakes up to $5 \mathrm{~mm}$ in diameter at $94 \mathrm{GHz}$ and for ice clouds where aggregation is the dominant process (i.e. not in the presence of deposition or riming). Similarly the Rayleigh-Gans approximation (RGA hereafter, Bohren and Huffman, 1983) is suited to describe the scattering properties of fluffy ice crystals with refractive indices close to unity (Tyynelä et al., 2013; Leinonen et al., 2013; Lu et al., 2013), and offers a computationally inexpensive way of estimating backscattering cross sections for complex particle shapes.

However, recent studies (Kim, 2006; Liu, 2008a; Tyynelä et al., 2011) have shown that for size parameters larger than 2 (which roughly correspond to maximum sizes of 5, 2, 1.4 and $0.9 \mathrm{~mm}$ at $35,94,140$ and $220 \mathrm{GHz}$, respectively) the details of the crystal shapes become increasingly important. Above such size parameters, backscattering cross sections for aggregate and fractal snowflakes can easily deviate by one (two) orders of magnitude at $35 \mathrm{GHz}(94 \mathrm{GHz})$ from the soft-spheroid model. At larger frequencies the differences become even more extreme. This is clearly seen in Fig. 4 where the backscattering cross sections for many different particle habits are shown at 35 (top) and $220 \mathrm{GHz}$ (bottom panel).

While at $35 \mathrm{GHz}$ only ice crystals with masses greater than $0.3-0.4 \mathrm{mg}$ show shape effects, at $220 \mathrm{GHz}$ extremely large departures from spheroid approximation are observed already for masses above $0.02 \mathrm{mg}$. At small masses spherical models do converge to the Rayleigh approximation while non-spherical shapes are slightly departing from such values (e.g. at vertical incidence and for perfectly oriented spheroids with axial ratio $0.6, \sigma_{\text {back }} / \sigma_{\text {Rayleigh }}=1.21$; Hogan et al., 2012). Aggregates of rosettes, bullet rosettes and hexagonal columns tend to be very efficient reflectors at $220 \mathrm{GHz}$. Similarly spheroids with larger densities (like those with density parameterized according to Matrosov, 2007) and mass larger than $0.1 \mathrm{mg}$ backscatter $1.4 \mathrm{~mm}$ radiation almost an order of magnitude more strongly than spheroids with the same mass but smaller densities (like those with density parametrized according to Hogan et al., 2012). Although the spheroid approximation only starts to break down in the presence of large snowflakes at 35 and $94 \mathrm{GHz}$, at $220 \mathrm{GHz}$ it will not be possible to describe the vast majority of snowflakes with a spheroidal approximation, even from a pure backscattering point of view. Similarly, the magenta dash-dotted line in Fig. 4 represents the behaviour of the backscattering cross section predicted according to RGA with the form factor and with the mass-density relationship proposed by Westbrook et al. (2006, 2008) and by Brown and Francis (1995), respectively. Overall the agreement with DDA models seems to be much better than that for spheroidal models, though the RGA results tend to underestimate the corresponding DDA backscattering cross sections (Petty and Huang, 2010; Tyynelä et al., 2013). Moreover, while simplified scattering models are useful for radar-only applications, they appear to fail for applications (e.g. combined radar/radiometer observations) where a coherent picture of all scattering properties (backscattering, attenuation, phase function) is needed.

\section{Retrieval methods using $G$ band radars}

For each of the cloud themes introduced in Sect. 2, we discuss in this section the benefit of introducing $\mathrm{G}$ band radar observations to multi-wavelength observations. 

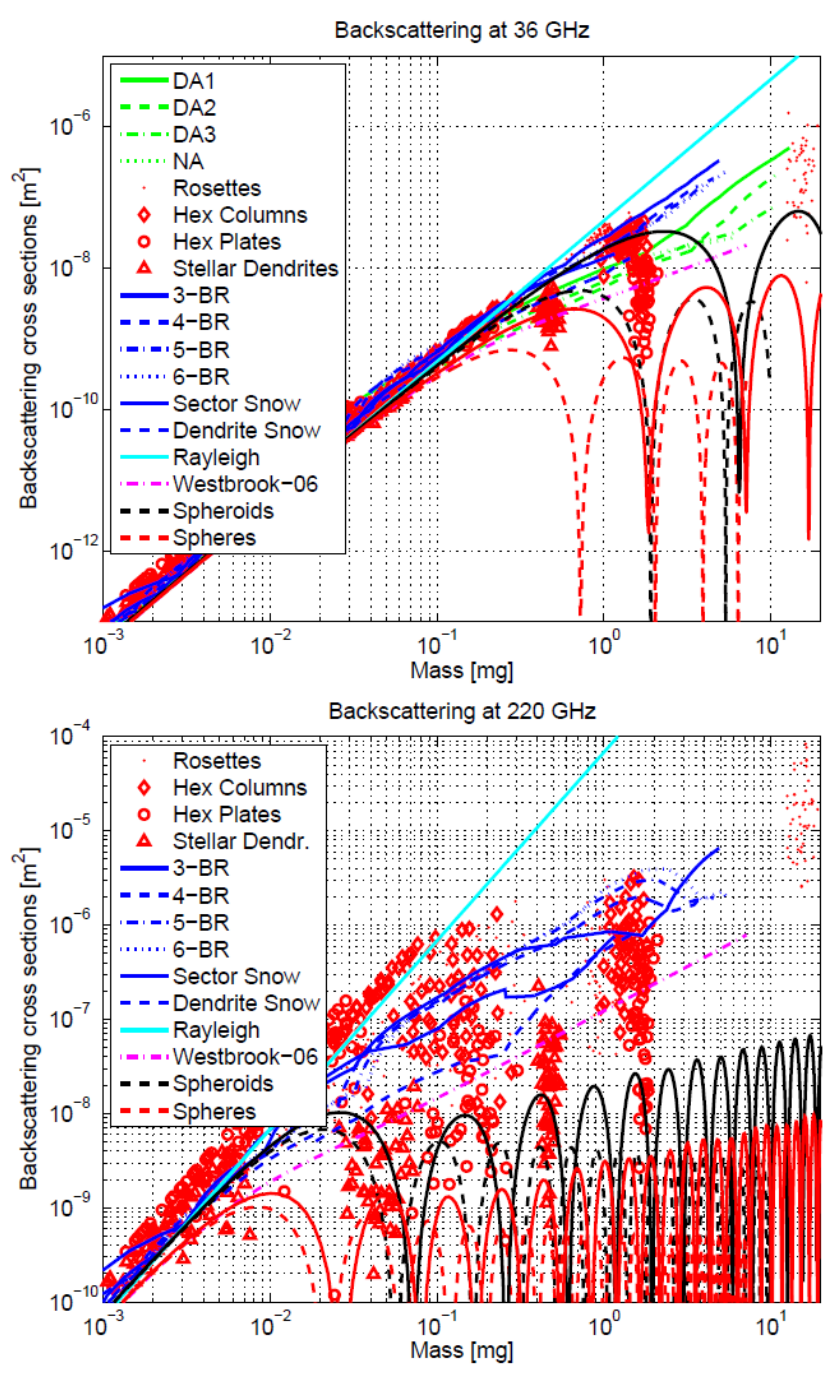

Figure 4. Backscattering cross sections for different habits as a function of ice crystal mass. Results from DDA data sets (Liu, 2008a; Petty and Huang, 2010; Tyynelä et al., 2011), for soft spheres and 0.6 axial ratio spheroids (following the snow densities proposed in Hogan et al. (2012) (dashed) and in Matrosov (2007) (continuous lines)) and the Rayleigh-Gans approximation according to Westbrook et al. (2006) (magenta dash-dotted) have been included.

\subsection{Boundary layer cloud profiling}

Thanks to significantly higher dual-wavelength attenuation compared to the 35-94 GHz pair (Fig. 2) the inclusion of a frequency within the $\mathrm{G}$ band has the clear advantage of increasing the accuracy of dual wavelength ratio LWC profiling techniques, even for clouds with very low reflectivities (e.g. fogs). DWR is defined as DWR $=10 \log _{10}\left(Z_{i} / Z_{j}\right)$ where $Z_{i}$ and $Z_{j}$ are the radar reflectivities measured at frequencies $i$ and $j$ where $i<j$. As noted in Hogan et al. (2005) there are three error sources in the dual-wavelength absorption technique: (1) random errors associated with the reflectivity

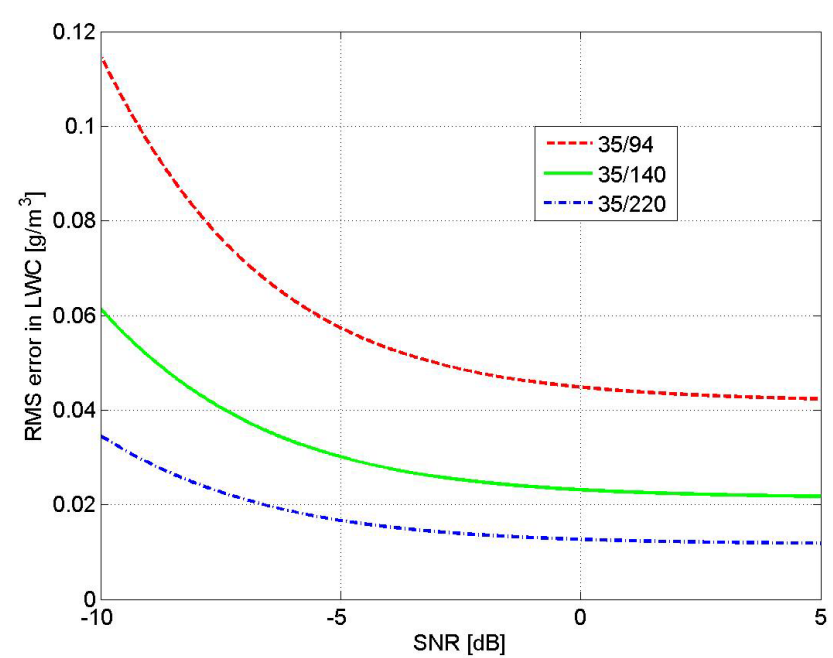

Figure 5. Errors in retrieved LWC using $35 / 94 \mathrm{GHz}, 35 / 140 \mathrm{GHz}$ and $35 / 220 \mathrm{GHz}$ radar frequency pairs vs. the single-pulse signalto-noise ratio. A vertical resolution of $150 \mathrm{~m}$ ( 2 gates), a one minute dwell time, $T=10^{\circ} \mathrm{C}$, a spectral width of $0.3 \mathrm{~m} \mathrm{~s}^{-1}$ and a pulse repetition frequency of $6250 \mathrm{~Hz}$ at all frequencies have been assumed.

measurement; (2) errors in the temperature profile which affect uncertainties in the gas absorption profile; (3) the presence of non-Rayleigh targets within the radar backscattering volume. These three errors sources are now discussed separately.

The same procedure followed by Hogan et al. (2005) is reproduced to show that random errors of $10 \mathrm{mg} \mathrm{m}^{-3}$ for $150 \mathrm{~m}$ vertical resolution and $1 \mathrm{~min}$ integration time are achievable when including the $35-220 \mathrm{GHz}$ pair (Fig. 5) in correspondence to targets with the signal to noise ratio exceeding $0 \mathrm{~dB}$. This roughly corresponds to a factor of 4 improvement in accuracy compared to the $35-94 \mathrm{GHz}$ pair.

Because of the attenuation caused by atmospheric gases increasing with higher frequency, an underestimation of the temperature in a saturated cloud environment causes an underestimation of the water vapour amount within the cloud and of its contribution to the gas dual-wavelength attenuation, which in turn leads to an overestimation in LWC. In correspondence to a $1^{\circ}$ error in temperature, the LWC error is steadily increasing from $5,7.5$ and $12 \mathrm{mg} \mathrm{m}^{-3}$ at $0^{\circ} \mathrm{C}$, to 10 , 14 and $23 \mathrm{mg} \mathrm{m}^{-3}$ at $10^{\circ} \mathrm{C}$ and to 22,29 and $45 \mathrm{mg} \mathrm{m}^{-3}$ at $20^{\circ} \mathrm{C}$, for the $35-94 \mathrm{GHz}, 35-140 \mathrm{GHz}$ and the $35-220 \mathrm{GHz}$ pairs, respectively. Because of the increase effect of the environment conditions onto the retrieval with increasing frequency this again suggests that $\mathrm{G}$ band radars can provide a real breakthrough only in environments that are not particularly warm (i.e. mid-/high-latitude liquid water clouds). On the other hand, the large sensitivity to water vapour amount can be used to gain insight into water vapour profiles.

When observing drizzling clouds, the presence of drizzle drops introduce Mie effects in the backscattering and in the 

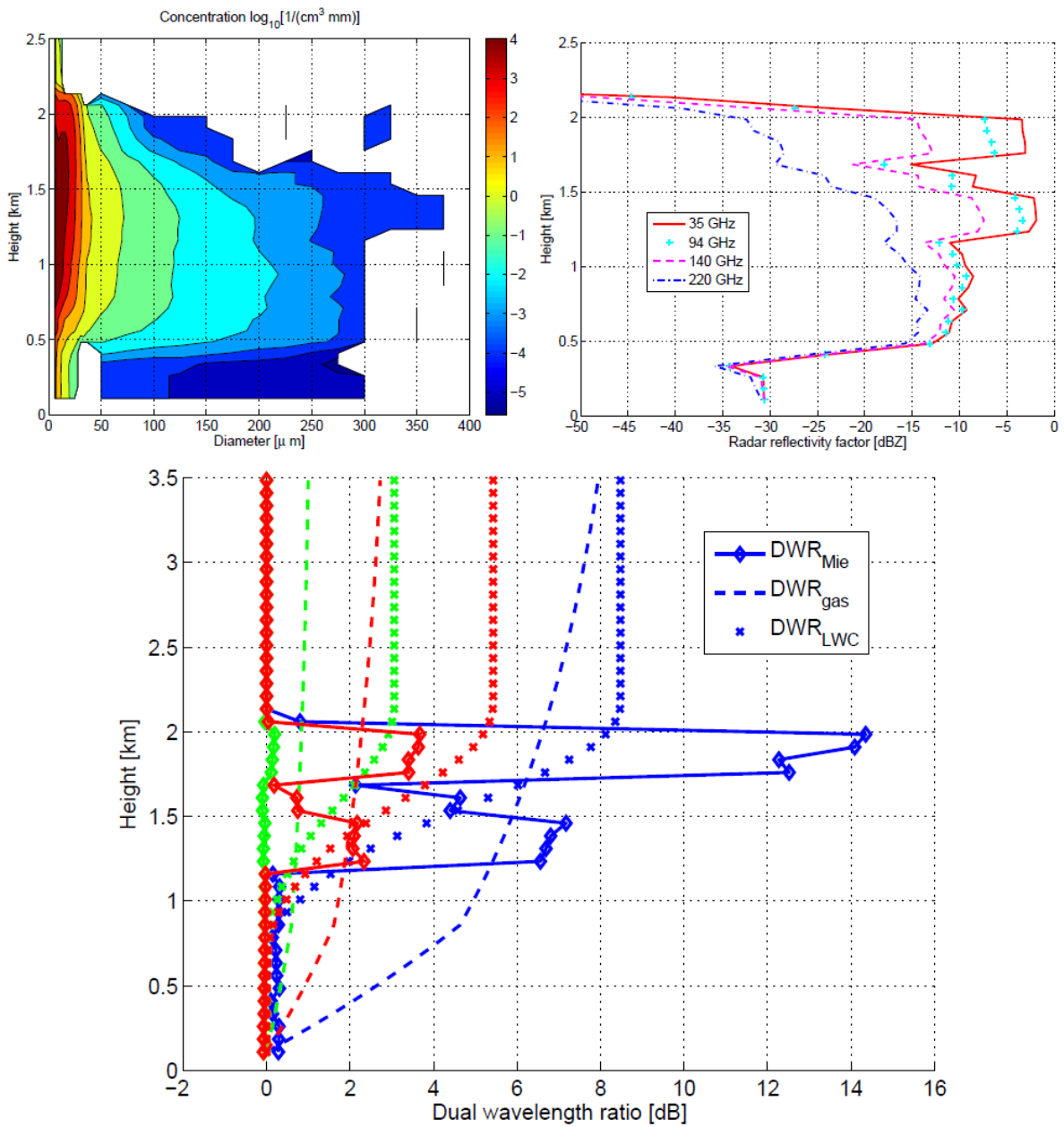

Figure 6. Top left: spectral density of liquid water content vs. diameter for a drizzling stratocumulus cloud as measured during the ASTEX campaign by the Forward Scattering Spectrometer Probe and the 2-D cloud probe on board the UK Met Office C-130 aircraft. Top right: simulated reflectivity factor at 35, 94, 140 and $220 \mathrm{GHz}$. Bottom: different DWR (dual wavelength reflectivity ratio) components simulated for different frequency pairs: $35-220 \mathrm{GHz}$ (blue), 35-140 GHz (red), 35-94 GHz (green).

attenuation coefficients, both effects contributing to a reduction of the measured reflectivity at higher frequencies. This is clearly demonstrated in Fig. 6 where radar reflectivities for four different frequencies $(35,94,140$ and $220 \mathrm{GHz})$ are simulated using a profile observed by the UK Met Office C-130 aircraft from stratocumulus clouds obtained during the ASTEX campaign (June 1992). The size distribution was measured using the Forward Scattering Spectrometer Probe and the 2-D cloud probe, which together measure droplets ranging in diameter from 6.5 to $800 \mu \mathrm{m}$. The top left panel in Fig. 6 shows the vertical profile of the liquid water spectral density; while the bulk of the liquid water is contained in the droplets smaller than around $30 \mu \mathrm{m}$ in diameter, drizzle drops up to $350 \mu \mathrm{m}$ are also present.

The presence of a few drizzle drops produces large Mie effects, especially at $220 \mathrm{GHz}$ (see the diamond line in the bottom panel of Fig. 6), and it is clear that disentangling the Mie contribution from the attenuation effects is not straightforward. The acquisition of complete Doppler spectra can hugely help in this respect (Tridon et al., 2013). If the different radars are beam- and volume-matched, we can expect that the spectra received at the different frequencies will be identical (within the spectral noise) in the Doppler region corresponding to the Rayleigh component, whilst they will differ in the part of the Doppler spectrum corresponding to the (faster falling) drizzle particles that produce Mie effects.

This is illustrated in Fig. 7, where the methodology described in Kollias et al. (2011) is applied to simulated Doppler spectra at 35 and $220 \mathrm{GHz}$ (red and blue curves, respectively) for a drizzling stratocumulus, parameterized by the superposition of two log-normal distributions with cloud and drizzle concentrations $N_{\mathrm{c}}=250 \mathrm{~cm}^{-3}$ and $N_{\mathrm{d}}=$ $3 \times 10^{-5} \mathrm{~cm}^{-3}$, number median radius $r_{\mathrm{c}}=6.5 \mu \mathrm{m}$ and $r_{\mathrm{d}}=$ $150 \mu \mathrm{m}$ and with logarithmic widths $\sigma_{\mathrm{c}}=0.35$ and $\sigma_{\mathrm{d}}=$ 0.3 , respectively. The cloud component is contributing the most towards the LWC $\left(\mathrm{LWC}_{\mathrm{c}} \approx 0.5 \mathrm{~g} \mathrm{~m}^{-3}\right.$ while $\mathrm{LWC}_{\mathrm{d}}=$ 


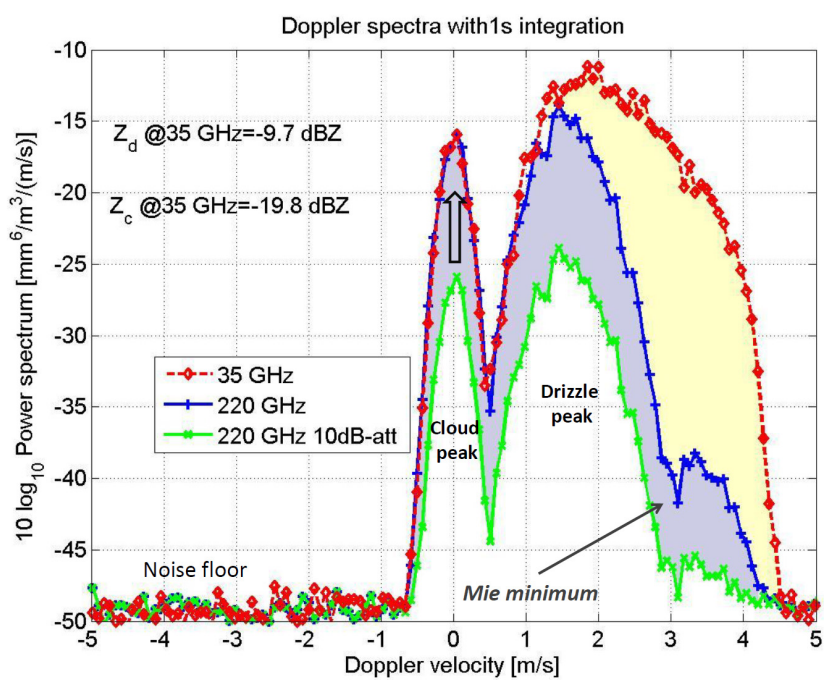

Figure 7. Example of 35 and $220 \mathrm{GHz}$ Doppler spectra simulated using a bimodal PSD with a cloud and a drizzle component. The single-pulse signal-to-noise ratio is assumed to be equal to $-25 \mathrm{dBZ}$ for both systems. The black arrow indicates the Rayleigh adjustment.

$6 \times 10^{-4} \mathrm{~g} \mathrm{~m}^{-3}$ ); in contrast, the drizzle component is driving the radar reflectivity $\left(Z_{\mathrm{c}}[35 \mathrm{GHz}]=-19.8 \mathrm{dBZ}\right.$ while $\left.Z_{\mathrm{d}}[35 \mathrm{GHz}]=-9.7 \mathrm{dBZ}\right)$. At $220 \mathrm{GHz}$ the reflectivity from the cloud (Rayleigh) component remains unchanged whereas the drizzle reflectivity is drastically reduced $\left(Z_{\mathrm{d}}[220 \mathrm{GHz}]=\right.$ $-15 \mathrm{dBZ}$ ). The yellow region accounts for the $5.3 \mathrm{~dB}$ loss of reflectivity caused by Mie effects. The magnitude of the Mie effects can be disentangled by integrating the yellow area between the two spectra. In general, the higher frequency spectrum will be attenuated more and will therefore appear more like the green line depicted in Fig. 7. In such a case, the spectrum at the highest frequency should firstly be shifted upward (arrow in Fig. 7) until adjusted to match the Rayleigh region of the spectrum measured at the lowest frequency. The area corresponding to the blue region is in fact a measure of the total dual-wavelength attenuation along the corresponding radar path. Of course, this methodology works as long as all relevant spectral features of the attenuated profile remain well above the noise floor. The proposed technique has the unique potential of disentangling Mie and dual-wavelength attenuation contributions and of characterizing simultaneously the cloud and the drizzle component of stratocumulus clouds. Experimental support for the validity of such an approach is provided for rain conditions at $35 / 94 \mathrm{GHz}$ by Tridon et al. (2013).

A better characterization of the drizzle component can also be achieved via dual wavelength velocity (DWV) measurements, i.e. the difference between the mean Doppler velocity measured at two different wavelengths. The left panel of Fig. 8 shows DWV as a function of the median volume drop diameter, $D_{0}$, for the $35-220 \mathrm{GHz}$ pair. A gamma drop size
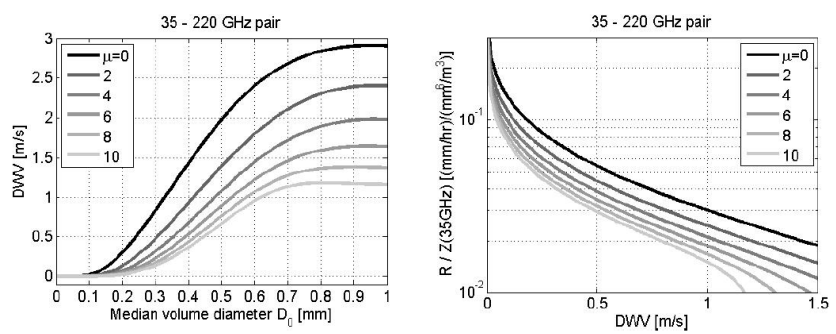

Figure 8. Left: dual-wavelength Doppler velocity as a function of the median volume drop diameter, $D_{0}$, for the $35-220 \mathrm{GHz}$ pair. The different curves are the results of different shape parameters $\mu$ for a gamma DSD. Right: ratio of drizzle rate $R$ to radar reflectivity measured at $35 \mathrm{GHz}$ as a function of dual-wavelength Doppler velocity. Note that for $0.25<\mathrm{DWV}<1 \mathrm{~m} \mathrm{~s}^{-1}$ an estimate of $R / Z$ can be made to within $\approx \pm 30 \%$ without knowledge of $\mu$.

distribution (DSD) has been assumed with $\mu$ values ranging between 0 and 10 (following O'Connor et al., 2005; Westbrook et al., 2010). The DWV shows sensitivity even to relatively small drops (i.e. $D_{0} \approx 300 \mu \mathrm{m}$ ). The right panel of Fig. 8 shows the ratio of drizzle rate $R$ to the radar reflectivity of the drizzle drops at $35 \mathrm{GHz}$, plotted as a function of DWV. We find that for $0.25<\mathrm{DWV}<1 \mathrm{~m} \mathrm{~s}^{-1}$, the ratio $R / Z$ is not strongly sensitive to the shape parameter $\mu$, and $R / Z$ can be estimated to within around $30 \%$ without prior knowledge of $\mu$. This means that, given DWV and $Z$ at $35 \mathrm{GHz}$, drizzle rates can be measured to within $30 \%$, an accuracy comparable with methods like the one proposed by Westbrook et al. (2010). In this case however, the method works both below cloud base, and within the cloud, since DWV is not affected by attenuation, and $Z$ at $35 \mathrm{GHz}$ is attenuated very little by liquid water. The only underlying assumption is that $Z$ and $V$ are dominated by drizzle and not by the cloud component, which could be verified by using spectral information (e.g. using spectral skewness following Kollias et al., 2011).

Finally, we note that at $220 \mathrm{GHz}$ the first minimum in raindrop backscattering cross sections is occurring for diameters around $0.72 \mathrm{~mm}$ (and therefore in correspondence to fall speeds of $3 \mathrm{~m} \mathrm{~s}^{-1}$, Lhermitte, 1990), so is therefore already visible in drizzle precipitation (see Fig. 7). A similar feature occurs at $94 \mathrm{GHz}$ for a diameter of $1.65 \mathrm{~mm}$ and a corresponding fall speed of $5.8 \mathrm{~m} \mathrm{~s}^{-1}$ and has been the basis for a vertical wind retrieval technique as proposed by Kollias et al. (2002) which has been implemented into an operational wind retrieval scheme by Giangrande et al. (2010). Preliminary computations demonstrate that the first minimum in the $220 \mathrm{GHz}$ Doppler spectrum can be detected for drizzle/light rain with $D_{0}>0.23 \mathrm{~mm}$, and for turbulence broadening lower than $0.2 \mathrm{~m} \mathrm{~s}^{-1}$, thus extending the range of applicability beyond that of the $94 \mathrm{GHz}$ vertical wind technique. 


\subsection{Cirrus and mid-level ice clouds}

\subsubsection{Sizing: dual-wavelength ratio method}

The methodology of using reflectivity measurements at two different frequencies to size particles in ice clouds is well established (e.g. Matrosov, 1998; Hogan and Illingworth, 1999; Hogan et al., 2000; Matrosov et al., 2005). The essential idea is that one frequency is chosen such that the particles are relatively small compared to the wavelength (in, or close to the Rayleigh scattering regime), while the second frequency is chosen such that particle dimensions are comparable to the wavelength (non-Rayleigh scattering). The non-Rayleigh scenario leads to destructive interference between parts of the particle separated by half a wavelength, and a reduction in reflectivity relative to that measured for the first frequency (a more detailed explanation is given by Muinonen et al., 2011). The reduction is a function of the size of the particle, and hence, the average size of the ice particles in clouds probed in this manner can be determined. Hogan and Illingworth (1999) investigated the potential of dual-wavelength radar measurements from a space-borne instrument to size particles in cirrus clouds, including frequencies above $100 \mathrm{GHz}$. They assumed an exponential size spectrum and approximated the ice particles by spheres using Mie theory. Here we extend their analysis to include a more realistic size spectrum and scattering model. The particles are assumed (as in Hogan and Illingworth, 1999) to be aggregates. However, rather than approximate these as spherical mixtures of air and ice inclusions, we make use of the results from Westbrook et al. $(2006,2008)$ who calculated the average scattering properties of a large ensemble of realistic aggregate geometries. For the PSD, Field et al. (2005) developed a parametrization based on in situ measurements from stratiform ice cloud over the British Isles which captures the quasi-bimodal shape of real size spectra and is more realistic than the simple exponential PSD used by Hogan and Illingworth (1999). For simplicity we will initially assume that the relationship between the mass $m$ and maximum dimension $D$ of the particles follows the empirical relationship of Brown and Francis (1995); the results from Hogan et al. (2006) and Heymsfield et al. (2010) confirm that this is a realistic approximation for many ice clouds. The problem of how to identify cases where the particles are more or less dense is considered in Sect. 4.2.3.

Figure 9 shows the resulting dual-wavelength reflectivity ratio, DWR, as a function of the average particle size $D^{*}$ (defined by Field et al., 2005 as the ratio of the third and second moments of the PSD). The value of DWR is a measure of the size of the ice particles: for larger particles, a larger dualwavelength ratio is observed. Note that DWR is also independent of the total concentration of particles in the distribution.

It is clear from Fig. 9 that the greater the frequency separation, the greater the dual-wavelength ratio for a given particle size. Whilst for the $35-94 \mathrm{GHz}$ combination average particle

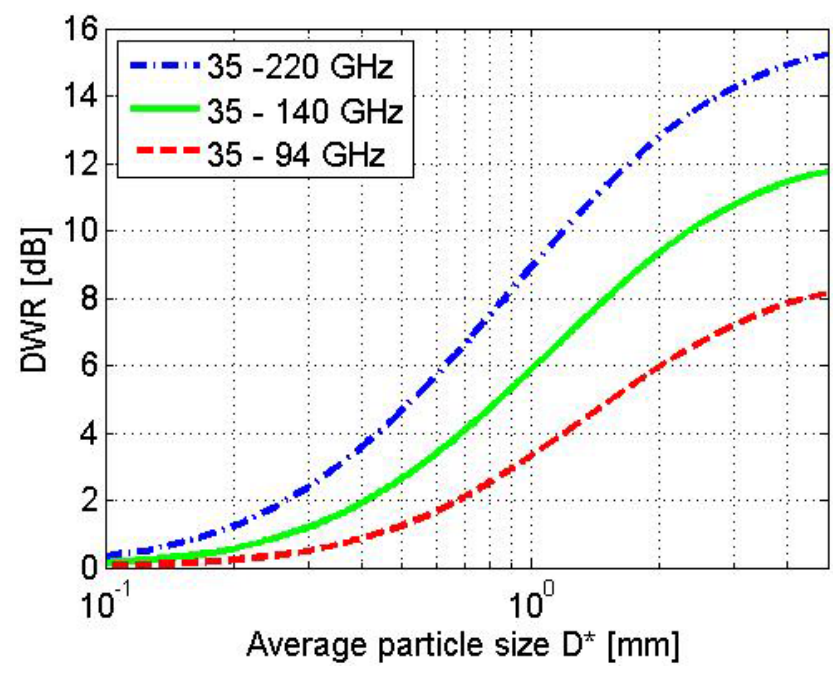

Figure 9. Dual-wavelength ratio as a function of average particle size computed for various pairs of wavelengths.

sizes of $700 \mu \mathrm{m}$ are needed to measure a $2 \mathrm{~dB}$ DWR, for a $35-220 \mathrm{GHz}$ combination a $2 \mathrm{~dB}$ DWR is obtained for particles only $260 \mu \mathrm{m}$ in size. This illustrates the much greater sensitivity of a $G$ band system for sizing relatively small cirrus particles compared with conventional frequencies. A 35$140 \mathrm{GHz}$ combination yields results lying between the other two pairs $\left(D^{*}=400 \mu \mathrm{m}\right.$ at DWR $\left.=2 \mathrm{~dB}\right)$.

Hogan et al. (2000) presented observations of cirrus at 35 and $94 \mathrm{GHz}$, and they used the DWRs to estimate particle size in the cloud. However, this was only possible in the lower portion of a relatively deep ice cloud, and Hogan et al. (2000) remarked that the technique does not work in many cirrus clouds because the particles are too small. This situation is dramatically improved for a $35-220 \mathrm{GHz}$ combination since Fig. 9 indicates that particles a factor $\sim 3$ smaller can be reliably sized. Field et al. (2005) shows that once the characteristic size of the PSD is known, along with another moment of the distribution (specifically the reflectivity at $35 \mathrm{GHz}$ ) the complete PSD can be derived and other moments such as ice water content and optical extinction can be computed.

This improved sensitivity to small particles is very valuable, but also presents a potential practical difficulty. While Hogan et al. (2000) cross-calibrated their two radars by assuming DWR was $0 \mathrm{~dB}$ at cloud top where the particles are small enough to be in the Rayleigh regime, this is not possible if a $220 \mathrm{GHz}$ radar is used, since even these small particles will likely be affected to some extent by Mie scattering, given the calculations shown in Fig. 9. In addition, there may be a non-negligible attenuation by the ice particles themselves throughout the depth of the ice cloud layer (Hogan and Illingworth, 1999) at these G band frequencies (Sect. 3.2). The solution to this issue is analogous to the approach taken in Sect. 4.1 for boundary layer clouds, and 


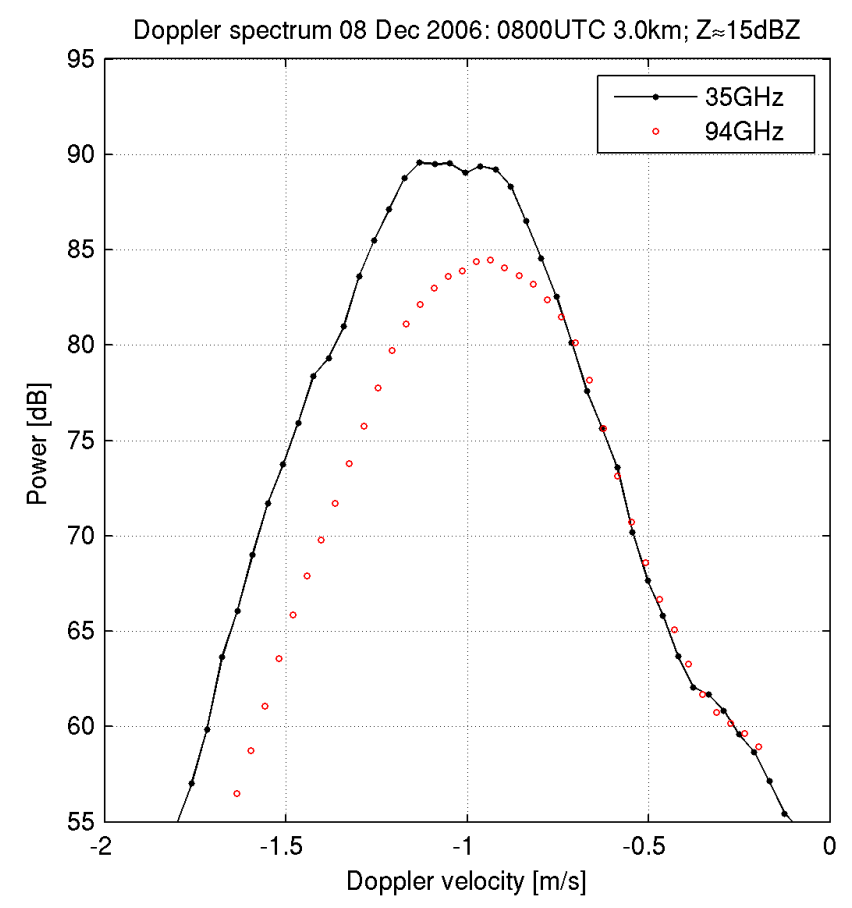

Figure 10. Example Doppler spectra recorded at 35 and $94 \mathrm{GHz}$ in a deep ice cloud. The power (abscissa) is in arbitrary units [dB].

makes use of information in the Doppler spectrum measured at the two frequencies. Since a distribution of particle sizes is present in the cloud, there will be some small ice particles present which are Rayleigh scatterers at all frequencies, and some larger particles which are non-Rayleigh scatterers. This is revealed clearly through analysis of the Doppler spectrum. Figure 10 shows a pair of Doppler spectra sampled simultaneously in a deep ice cloud by the 35 and $94 \mathrm{GHz}$ radars at the Chilbolton Observatory in the UK (see Illingworth et al., 2007, for details of the radars used). The integration time was $1 \mathrm{~s}$ for both radars. In this case, negative velocities denote particles falling towards the radar. The slower falling particles $\left(0.1-0.7 \mathrm{~m} \mathrm{~s}^{-1}\right)$ have identical reflectivities at both frequencies, and hence are Rayleigh scatterers; meanwhile the larger, faster falling particles $\left(0.7-1.7 \mathrm{~m} \mathrm{~s}^{-1}\right)$ have significantly lower reflectivity at $94 \mathrm{GHz}$ than at $35 \mathrm{GHz}$, and hence are non-Rayleigh scatterers. Based on these results, it seems promising that a correction for attenuation at 140 or $220 \mathrm{GHz}$ can be made at each range gate simply by shifting the Doppler spectrum until the reflectivity from the small particles matches that recorded at $35 \mathrm{GHz}$.

\subsubsection{Sizing: dual-wavelength Doppler velocity method}

The challenges of accurate cross-calibration of reflectivity data in the presence of non-Rayleigh scatterers and attenuating particles motivate an alternative approach which is not sensitive to calibration errors. Matrosov (2011) showed that the difference in mean Doppler velocity measured at 35

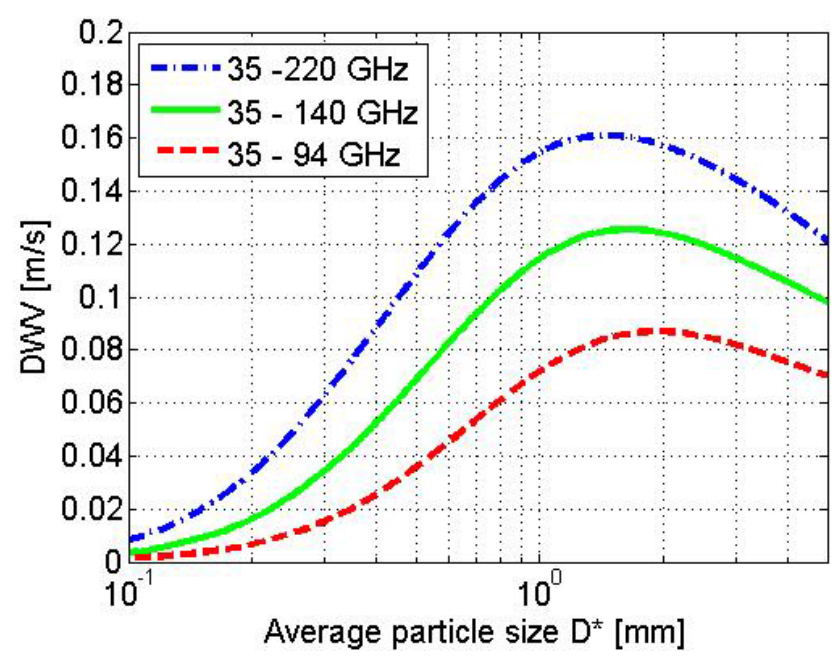

Figure 11. Difference in mean Doppler velocity as a function of average particle size computed for various wavelength pairs.

and $94 \mathrm{GHz}$ is, like DWR, a function of particle size. Here we extend Matrosov's calculations to frequencies > $94 \mathrm{GHz}$. We use the same PSD, mass-size relationship and scattering model used for the DWR calculations in the previous section. Terminal velocities of the particles are computed explicitly from their mass, maximum dimension, and area using Heymsfield and Westbrook (2010)'s method; the areadiameter relationship used here is that proposed by Mitchell (1996) for aggregates.

Figure 11 shows DWV as a function of the average particle size $D^{*}$ computed for various frequency pairs. Like the dual-wavelength ratio, DWV increases as the size of the particles increases, and it is independent of the concentration of particles in the volume. We observe that DWV is larger for the 35-140 and 35-220 GHz combinations than for the $35-94 \mathrm{GHz}$ pair used by Matrosov (2011). At $D^{*}=300 \mu \mathrm{m}$ the effect is a factor of 3 larger for $35-220 \mathrm{GHz}$ than for $35-94 \mathrm{GHz}$, again indicating the much stronger sensitivity to smaller particles when a $\mathrm{G}$ band radar is employed. However, for all frequency pairs DWV is rather small in magnitude, and as pointed out in Matrosov (2011), beam-matching and very accurate pointing of the two radars are essential conditions for the technique to work (for a $15 \mathrm{~m} \mathrm{~s}^{-1}$ horizontal wind speed, a $0.1^{\circ}$ pointing error in one of the radars can lead to a $0.025 \mathrm{~m} \mathrm{~s}^{-1}$ bias in DWV, making it challenging to size small particles accurately). Close co-location of the radar beams is also very important since we have assumed that any vertical air motion cancels out, since both radars sample the same region of cloud. Imperfect co-location will lead to random errors in DWV, again making retrievals of small particles difficult. 


\subsubsection{Discrimination of different ice particle density relationships}

So far we have assumed that the relationship between a particle's mass and diameter may be described by the well-known relationship of Brown and Francis (1995), which has been validated by Hogan et al. (2006) and Heymsfield et al. (2010). However, this may not be suitable for all clouds, and indeed Hogan et al. (2006) noted that in mixed-phase regions the agreement between radar and in situ data was poor when Brown and Francis densities were assumed. Likewise, Matrosov (2011) observed DWV values as high as $0.25 \mathrm{~m} \mathrm{~s}^{-1}$ using 35 and $94 \mathrm{GHz}$ radars. This is not consistent with the results in Fig. 11 for 35 and $94 \mathrm{GHz}$ radars, and this is likely because the density of the particles in that cloud was larger than that predicted by the Brown and Francis relationship. One way to discriminate between different density assumptions is to investigate the relationship between DWV and DWR. Figure 12 shows calculations of this relationship for the $35-220 \mathrm{GHz}$ frequency pair, initially assuming Brown and Francis densities (solid curve). Also shown in the figure are predictions for uniformly doubled/halved particle densities obtained by correcting the prefactor in the mass-diameter relationship. It is clear that if DWR and DWV can be measured with sufficient accuracy, different density assumptions can be discriminated in this way. For a DWR of $6 \mathrm{~dB}$ the dual-wavelength Doppler velocity is $0.09 \mathrm{~m} \mathrm{~s}^{-1}$ for the low-density scenario, compared to $0.17 \mathrm{~m} \mathrm{~s}^{-1}$ for the high-density scenario. We remark that this sensitivity of DWV to the assumed density is contradictory to what Matrosov (2011) found in his sensitivity analysis. However, we hypothesize that this is due to his use of a simple velocity-diameter relationship to calculate the particle fall speeds, rather than considering the full dependence of particle fall speed on particle mass (Heymsfield and Westbrook, 2010).

\subsection{Microphysical characterization of precipitating snow}

At large particle sizes like those encountered during snowfall, the sizing capabilities of DWR techniques are impaired by the large uncertainties introduced by the wide variety of possible particle habits. DWRs for snow exponential PSD have been calculated as a function of the PSD slope parameter $\Lambda$ (inversely proportional to the median volume diameter $D_{0}$ ) for different pairs of radar frequencies. The strongest DWR signals are achieved by combining measurements in the $\mathrm{K}_{\mathrm{a}}$ band with those at one of the two $\mathrm{G}$ band frequencies here considered, 150 or $220 \mathrm{GHz}$. Unlike for frequency combinations where the higher frequency is still partly within the Rayleigh regime (e.g. $\mathrm{K}_{\mathrm{a}}-\mathrm{W}$ DWR, see Fig. 7 in Kneifel et al., 2011), the $\mathrm{K}_{\mathrm{a}}-220 \mathrm{GHz}$ frequency pair (shown in Fig. 13) is particularly promising, as there is a monotonic dependence of DWR on snow mean size. However, there is still

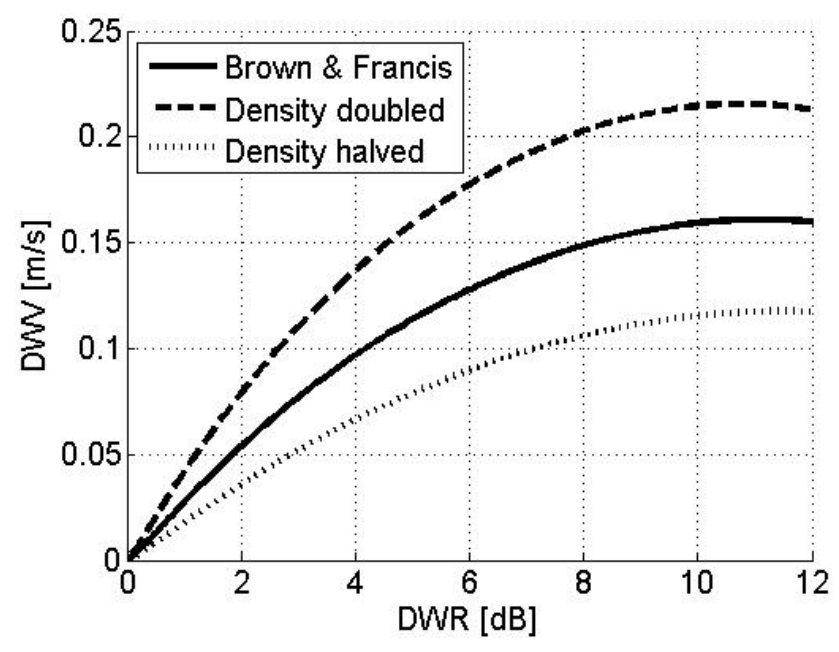

Figure 12. Difference in mean Doppler velocity DWV as a function of dual-wavelength reflectivity ratio, DWR. The thick solid line shows the prediction for the Brown and Francis density relationship, while the thinner dashed lines show the effect of doubling or halving the density of the particles.

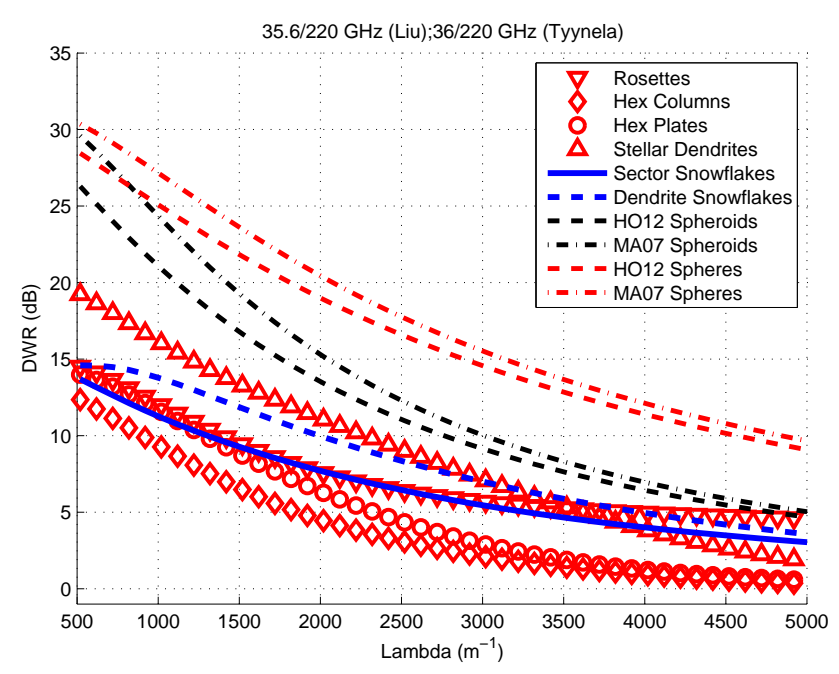

Figure 13. Dual-wavelength reflectivity ratio, DWR, as function of PSD slope coefficient $\Lambda$ for the $\mathrm{K}_{\mathrm{a}}-220 \mathrm{GHz}$ frequency pair for different crystal habits.

a strong dependence of DWR on ice particle habit, which is likely to introduce large ambiguities in particle characteristic size retrievals. This implies that knowledge of the particle habit is a necessary precondition to obtain the slope parameter $\Lambda$ (and therefore, snow water content and snowfall rate) from a DWR measurement.

Triple-frequency approaches have the potential to separate different snow particle habits and to narrow down the uncertainties in the slope parameter characteristic of the PSDs of ice and snow clouds (Kneifel et al., 2011). For instance, when considering triple frequency combinations and plotting 
two different pairs of DWR against one another (for example Fig. 14 in this study and Fig. 2 in Leinonen et al., 2012), it becomes theoretically possible to distinguish different snow particle habits. Remotely sounded observational evidence of non-spheroidal particles in snow has already been reported using this technique, based on co-located air-borne measurements in the $\mathrm{K}_{\mathrm{u}}, \mathrm{K}_{\mathrm{a}}$ and $\mathrm{W}$ bands (Leinonen et al., 2012). Figure 14 shows similar calculations to those performed by Leinonen et al. (2012) but using an additional frequency at $220 \mathrm{GHz}$. Owing to the larger dynamic range of DWR values and due to the higher sensitivity of the high-frequency DWR to small particles, separation between different habit modes should be achieved when adopting $\mathrm{G}$ band frequencies (compare top and bottom panel in Fig. 14). Once the predominant habit type has been identified, it is then possible to obtain an estimate of the median volume diameter or slope parameter $\Lambda$ (as denoted by the colour of the points plotted in Fig. 14).

It should be noted that the effects of attenuation on the radar measurements are not considered in these plots, i.e. it is implicitly assumed that an attenuation correction for gases and hydrometeors has already been applied to the actual measurements (e.g. via the Doppler spectra matching technique). At frequencies in the $\mathrm{G}$ band, attenuation due to snow increases strongly with frequency, and becomes increasingly sensitive to snow particle habit (see Fig. 3). However, the stronger attenuation at 150 and $220 \mathrm{GHz}$ also makes it easier to disentangle its contribution from Mie effects in multifrequency reflectivity profiles, thus enabling the attenuation signal to be used to provide further information on snow habit and snow water content. An example of how attenuation could be used in this way as part of a dual-frequency set-up is shown in Fig. 15. When plotting attenuation against DWR the different snow habits are clearly distinguishable, which also allows the PSD parameters to be inferred with less uncertainty. Note that according to our scattering database there is large variability in the attenuation due to snow habit, even more than in the attenuation measurements reported by Nemarich et al. (1988) and Wallace (1988) (indicated by the arrows in Fig. 15). As a result, the large values of snow dualwavelength attenuation and dual-wavelength effective reflectivities should significantly help in narrowing down the uncertainties related to snow microphysics.

\section{Recommended technical specifications for a $220 \mathrm{GHz}$ radar}

Though a stand-alone $G$ band system can have its own merit, the proposed suite of research applications for $\mathrm{G}$ band radars (boundary layer clouds, ice and snow over a wide range of temperatures) are possible if the proposed $\mathrm{G}$ band radars are deployed alongside a cloud radar for collecting dualwavelength radar measurements at a ground-based facility. As an initial configuration we recommend a vertically pointing 35/220 GHz dual-wavelength Doppler system, with the
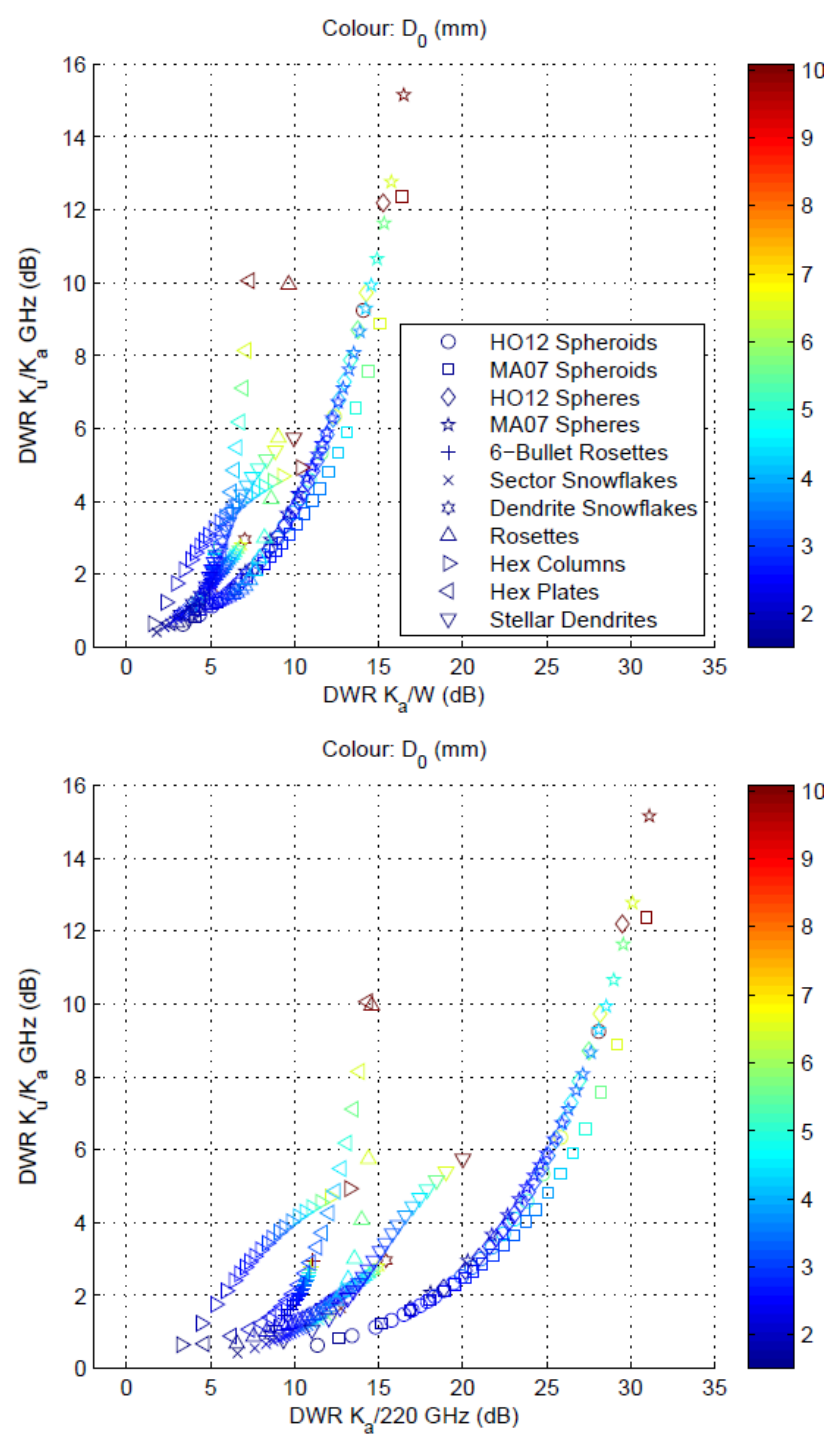

Figure 14. Dual-wavelength reflectivity (DWR) ratios plotted against one another in two different triple frequency combinations: $\mathrm{K}_{\mathrm{u}}-\mathrm{K}_{\mathrm{a}}-\mathrm{W}$ (top) and $\mathrm{K}_{\mathrm{u}}-\mathrm{K}_{\mathrm{a}}-220 \mathrm{GHz}$ (bottom).

second frequency well within the $\mathrm{G}$ band and the first frequency typically available at most cloud observatories. In addition to being co-located, the two radar systems should also have comparable sampling volumes, ability to collect radar Doppler spectra, and overlapping sensitivity at the reflectivity regimes where the dual-wavelength radar provide new (more sensitive) information about cloud microphysics.

There are important considerations that should affect the development of any future $\mathrm{G}$ band radar systems for atmospheric research. First of all, for the multi-frequency systems envisaged for synergetic observations, narrow beam widths are foreseen. Thus, short integration times $(\sim 1-2 \mathrm{~s}$ needed for averaging out spectral noise) are expected to average out possible antenna mismatches. As a result, matching the single-beam antenna $3 \mathrm{~dB}$ beam widths (i.e. deploying 
Table 1. Specifics for a dual-frequency system involving a $\mathrm{G}$ band radar at $220 \mathrm{GHz}$ for cloud studies. The KAZR system uses pulse compression (which provides an effective $10 \mathrm{~dB}$ gain in the MDT). A $6.5 \mathrm{~dB}$ noise figure has been used for all systems to compute the MDT.

\begin{tabular}{|c|c|c|c|c|}
\hline Specific/system Beam width $\left[{ }^{\circ}\right]$ & $\begin{array}{r}\text { KAZR } \\
0.3\end{array}$ & $\begin{array}{r}\text { MIRA-35 } \\
0.6\end{array}$ & $\begin{array}{r}\text { G-KAZR } \\
0.12\end{array}$ & $\begin{array}{r}\text { G-MIRA } \\
0.24\end{array}$ \\
\hline Antenna diameter ${ }^{\mathrm{a}}[\mathrm{m}]$ & 2.0 & 1.0 & 0.8 & 0.4 \\
\hline Fraunhofer distance $[\mathrm{m}]$ & 934 & 233 & 939 & 235 \\
\hline Power $[\mathrm{kW}]$ & 0.2 & 30 & 0.1 & 0.1 \\
\hline Pulse length ${ }^{\mathrm{b}}[\mu \mathrm{s}]$ & 0.2 & 0.2 & 0.2 & 0.2 \\
\hline Single pulse MDT @1 km [dBZ] & -35 & -41 & -46 & -40 \\
\hline $\operatorname{PRF}[\mathrm{kHz}]$ & $2.5-10$ & $2.5-10$ & $10-15$ & $10-15$ \\
\hline Nyquist velocity $\left[\mathrm{m} \mathrm{s}^{-1}\right]$ & $5.3-21.4$ & $5.3-21.4$ & $3.4-5.1$ & $3.4-5.1$ \\
\hline
\end{tabular}

a The KAZR antenna diameter at the ARM SGP site is $3.0 \mathrm{~m}$. ${ }^{\mathrm{b}}$ The proposed pulse length does not exclude the use of pulse compression schemes that use longer pulses with frequency modulation. The Fraunhofer distance is defined as $2 D^{2} / \lambda$

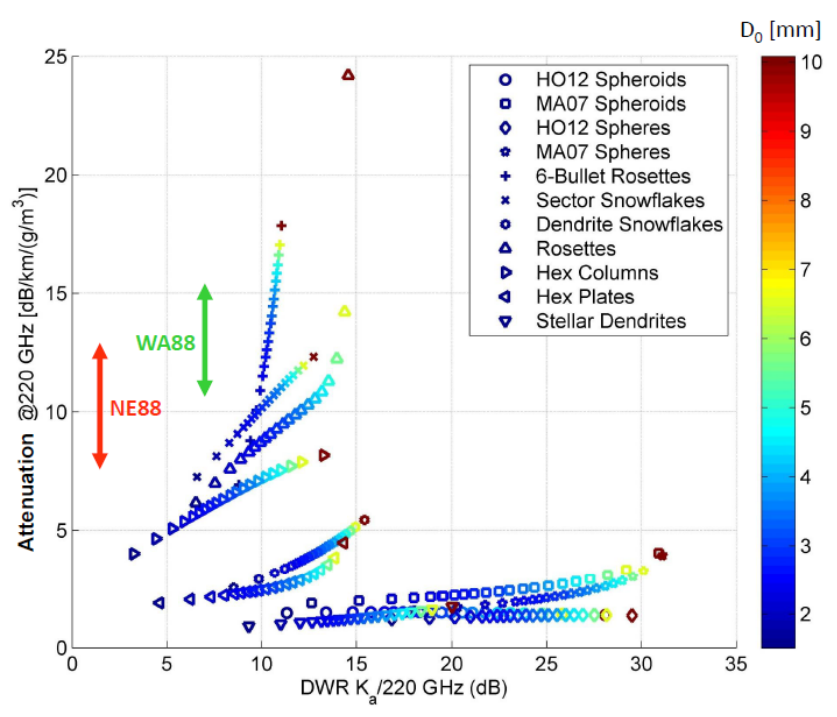

Figure 15. Snow attenuation per unit mass at $220 \mathrm{GHz}$ for different snow particle habits and PSDs (as indicated by the different colours), plotted against $\mathrm{K}_{\mathrm{a}}-220 \mathrm{GHz}$ DWR. Ranges of snow attenuation measured by Wallace (1988) and Nemarich et al. (1988) are illustrated by the arrows.

antennas with diameters linearly decreasing with increasing wavelength) does not seem an essential consideration for high quality dual-wavelength radar measurements as demonstrated by recent work (Tridon et al., 2013) conducted with the ARM-KAZR $\left(0.2^{\circ}\right)$ and the W-SACR $\left(0.3^{\circ}\right)$. However, it is crucial to match the integration time interval and the vertical range of the backscattering volume. This suggests using smaller beam widths at $\mathrm{G}$ band in order to increase sensitivity (proportional to the square of the dish diameter, $D$ ). However, to keep near-field effects (proportional to $D^{2} / \lambda$ ) at a comparable level for the two radars we trade-off the diameter of the dish $D$ to be proportional to the square root of the wavelength, $\lambda$. The single-pulse minimum detection threshold (MDT) at $1 \mathrm{~km}$ distance and the Fraunhofer distance for a $100 \mathrm{~W}$ G band system are shown in Fig. 16 for different

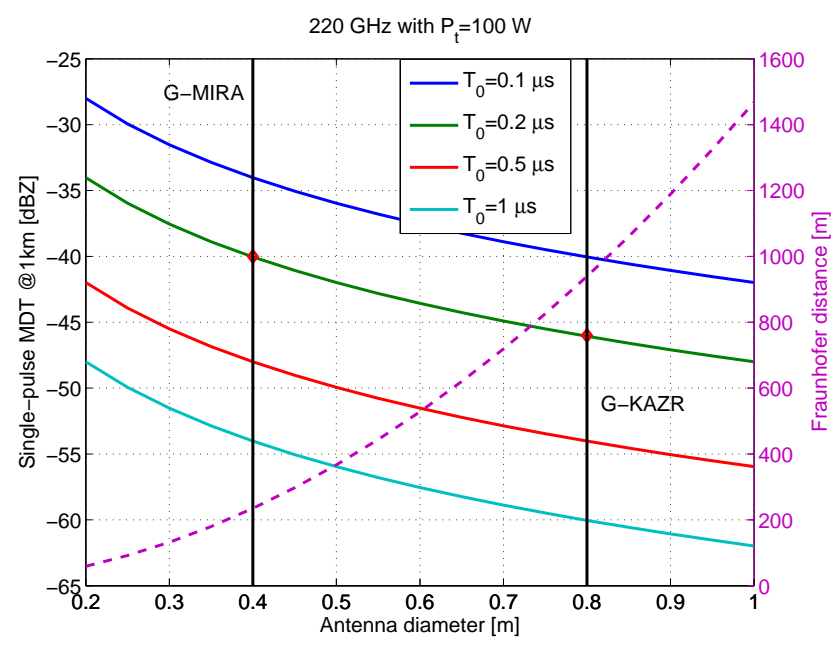

Figure 16. MDT (left $y$ scale) and Fraunhofer distance (right $y$ scale) as a function of the antenna diameter and for different pulse lengths $T_{0}$. The assumed transmitted power is $100 \mathrm{~W}$. A noise figure of $6.5 \mathrm{~dB}$ is assumed.

circular antenna sizes and for different pulse lengths. Note that this transmitted power seems feasible with state-ofthe-art klystron technology (Steer et al., 2007). Frequencymodulated continuous-wave solutions could also be adopted but state-of-the-art solid-state technology allows mean transmitted powers not exceeding $100 \mathrm{~mW}$, thus reducing sensitivity by more than $13 \mathrm{~dB}$ compared to the proposed pulsed system (the MDT scales linearly with the mean transmitted power).

In view of a dual-frequency configuration here we consider the two most widely used ground-based $35 \mathrm{GHz}$ systems in atmospheric research: the $\mathrm{K}_{\mathrm{a}}$ band ARM Zenith Radar (KAZR, Widener et al., 2012) and the MIRA-35 (http://www.metek.de/product-details/ vertical-cloud-radar-mira-35.html), to derive the associated technical specifications of a $220 \mathrm{GHz}$ radar that will be either co-located with a KAZR (G-KAZR) or with a MIRA-35 (G-MIRA). If we impose that the diameter of the dish is 
proportional to the square root of the wavelength (previous criterion) we end up with a diameter of 0.4 and $0.8 \mathrm{~m}$ for the G-MIRA and the G-KAZR, respectively (black vertical lines in Fig. 16). If we additionally match the vertical resolution of the KAZR and MIRA the MDT values are depicted as red diamonds in Fig. 16 and reported with the other specifications of the KAZR, MIRA-35 and G-KAZR and G-MIRA in Table 1 . The proposed pulsed $220 \mathrm{GHz}$ klystron system with a $100 \mathrm{~W}$ peak power is capable of achieving comparable or better single-pulse minimum detection thresholds than the $35 \mathrm{GHz}$ counterparts (see values in the seventh line in Table 1). This is certainly needed because of the larger attenuation suffered by G band systems (see Sects. 3.1 and 3.2). The G-KAZR and G-MIRA systems seem well suited for tackling the cloud problems described in this paper.

Incidentally, we note that at $G$ band there are no specific limitations to adopt pulse-compressed waveforms for the transmitted pulse, with the potential of further improving the MDT of the system. On the other hand, there are no T/R switches available at such high frequencies which triggers the choice of a bi-static system.

\section{Future work and conclusions}

Our understanding of the physical processes governing cloud and precipitation is currently limited by gaps in our ability to remotely observe vertical profiles of the underlying microphysics. It is clear that a significant leap forward in this understanding can only come from observation systems which provide an increasing number of independent measurements. This allows progression from under-constrained problems into more constrained problems where remote sensing observations can significantly reduce the uncertainties in the retrieved microphysics. Once this goal is reached then proper parameterizations can be developed, which can be adopted e.g. into passive or single frequency (under-constrained) retrievals. In this work we have proposed the use of multifrequency Doppler techniques, combining $35 \mathrm{GHz}$ radars with radars operating in the $G$ band, to significantly improve our profiling capabilities in three key areas: boundary layer, cirrus and mid-level ice, and snow-precipitating clouds. These cloud systems are characterized by particle hydrometeor sizes in the millimetre range. This implies that millimetre-radar backscattering signals are not simply proportional to the square of the mass of the scatterer like at centimetre (or longer) wavelengths, but present a weaker mass dependence. The reduction in reflectivities compared to the Rayleigh reference is related to particle size and habit, and carries critical information that can be injected into retrieval algorithms. For $1 \mathrm{mg}$ ice crystals, DWRs at $220 \mathrm{GHz}$ (with respect to the Rayleigh reference) can range from $10 \mathrm{~dB}$ to more than $40 \mathrm{~dB}$ depending on the shape model. Multiple frequency measurements (incorporating $\mathrm{G}$ band frequencies) of the same volume can provide very strong tests of the fidelity of ice scattering models and of the PSD and habit hydrometeor populations, as the different frequencies will accentuate contributions from different parts of the PSD and will be able to probe the monomer structure of the snowflake (Leinonen et al., 2013). For large ice crystals significant attenuation is produced as well, with the attenuation process being dominated by scattering. This affects radar measured reflectivities by introducing measurable attenuation effects (several $\mathrm{dBs}$ ) onto vertical and, even more notably, onto slanted profiles, and allows testing of the consistency between attenuation and backscattering electromagnetic modelling. By bridging towards the far-infrared, such measurements could facilitate the construction of electromagnetic modelling fully consistent across the electromagnetic spectrum, from microwave to visible.

This work demonstrates that multi-frequency radar techniques, which would combine observations from $\mathrm{G}$ band Doppler radars with $\mathrm{K}_{\mathrm{a}}$ or $\mathrm{W}$ band radar measurements, may significantly contribute to solving the microphysical deadlock in some key sectors of cloud physics. Given this premise, more than 30 years since the first measurements with such systems and after almost 25 years of inaction, we urge the entire remote sensing scientific community towards revitalizing the construction, deployment and exploitation of $\mathrm{G}$ band radars for cloud and precipitation studies. The deployment of such systems at mid/high altitude/latitude ground-based facilities (e.g. the ARM North Slope of Alaska, the Canadian Eureka site, the Chilbolton observatory (UK), the Zugspitze observatory (Germany), to name only a few) in synergy with lower-frequency radar systems (and additional active/passive remote sensing instrumentation already deployed) has great potential and can provide crucial information on cold precipitation processes, on vertical microphysical profiles of water clouds and on ice particle sizes and habits. The subsequent improvement in cloud parameterizations, which we anticipate given the availability of such measurements, would be invaluable in the future development of numerical weather prediction and global climate models.

Acknowledgements. We would like to thank Jon Eastment, John Bradford, Peter Huggard and Brian Moyna from the Rutherford Appleton Laboratory for valuable discussions on the practical development of $\mathrm{G}$ band radars. We also thank the staff at the Chilbolton Facility for Atmospheric and Radio Research for operating the 35 and $94 \mathrm{GHz}$ radars used in Fig. 10. The portion of work carried out by A. Battaglia was funded by NERC though the PERICLES project. N. Humpage was supported by the UK Centre for Earth Observation Instrumentation (CEOI) through the HIDRA4PPM project. The portion of work carried out by Tyynelä was supported by the Finnish Centre for Scientific Computing (CSC) and the Academy of Finland (contract 128328). The work done by S. Kneifel was supported by the German Academic Exchange Service (DAAD).

Edited by: F. S. Marzano 


\section{References}

Ackerman, T. P. and Stokes, G. M.: The Atmospheric Radiation Measurement Program, Physics Today, 56, 39-44, 2003.

Atlas, D.: The estimation of cloud content by radar, J. Meteorol., 11, 309-317, 1954.

Austin, R. T., Heymsfield, A. J., and Stephens, G. L.: Retrieval of ice cloud microphysical parameters using the CloudSat millimeter-wave radar and temperature, J. Geophys. Res., 114, D00A23, doi:10.1029/2008JD010049, 2009.

Aydin, K. and Walsh, T. M.: Millimeter wave scattering from spatial and planar bullet rosettes, IEEE T. Geosci. Remote Sens., 37, 1138-1150, doi:10.1109/36.752232, 1999.

Battaglia, A. and Delanöe, J.: Synergies and complementarities of CloudSat-CALIPSO snow observations, J. Geophys. Res., 118, 721-731, doi:10.1029/2012JD018092, 2013.

Battaglia, A., Tanelli, S., and Kollias, P.: Polarization diversity for millimeter space-borne Doppler radars: an answer for observing deep convection?, J. Atmos. Ocean Tech., 30, 2768-2787, doi:10.1175/JTECH-D-13-00085.1, 2013.

Benedetti, A., Stephens, G., and Vukicevic, T.: Variational assimilation of radar reflectivities in a cirrus model. II: Optimal initialization and model bias estimation, Q. J. Roy. Meteorol. Soc., 129, 301-319, 2003.

Bennartz, R., Shupe, M. D., Turner, D. D., Walden, V. P., Steffen, K., Cox, C. J., Kulie, M. S., Miller, N. B., and Pettersen, C.: July 2012 Greenland melt extent enhanced by low-level liquid clouds, Nature, 496, 83-86, doi:10.1038/nature12002, 2013.

Berg, W., L'Ecuyer, T., and Haynes, J. M.: The Distribution of Rainfall over Oceans from Spaceborne Radars, J. Appl. Meteorol. Clim., 49, 535-543, doi:10.1175/2009JAMC2330.1, 2010.

Bohren, C. F. and Huffman, D. R.: Absorption and Scattering of Light by Small Particles, John Wiley \& Sons, New York, 1983.

Bony, S. and Dufresne, J.-L.: Marine boundary layer clouds at the heart of tropical cloud feedback uncertainties in climate models, Geophys. Res. Lett., 32, L20806, doi:10.1029/2005GL023851, 2005.

Botta, G., Aydin, K., and Verlinde, J.: Modeling of microwave scattering from cloud ice crystal aggregates and melting aggregates: A new approach, IEEE Geosci. Remote Sens., 7, 572-576, doi:10.1109/LGRS.2010.2041633, 2010.

Botta, G., Aydin, K., Verlinde, J., Avramov, A. E., Ackerman, A. S., Fridlind, A. M., McFarquhar, G. M., and Wolde, M.: Millimeter wave scattering from ice crystals and their aggregates: Comparing cloud model simulations with $\mathrm{X}$ - and Kaband radar measurements, J. Geophys. Res., 116, D00T04, doi:10.1029/2011JD015909, 2011.

Brandau, C., Russchenberg, H., and Knap, W.: Evaluation of ground-based remotely sensed liquid water cloud properties using shortwave radiation measurements, Atmos. Res., 96, 366377, 2010.

Brown, P. R. A. and Francis, P. N.: Improved measurements of the ice water content in cirrus using a total-water probe, J. Atmos. Ocean Tech., 12, 410-414, 1995.

Buehler, S. A., Defer, E., Evans, F., Eliasson, S., Mendrok, J., Eriksson, P., Lee, C., Jiménez, C., Prigent, C., Crewell, S., Kasai, Y., Bennartz, R., and Gasiewski, A. J.: Observing ice clouds in the submillimeter spectral range: the CloudIce mission proposal for ESA's Earth Explorer 8, Atmos. Meas. Tech., 5, 1529-1549, doi:10.5194/amt-5-1529-2012, 2012.
Crewell, S. and Löhnert, U.: Accuracy of cloud liquid water path from ground-based microwave radiometry, 2, Sensor accuracy and synergy, Radio Sci., 38, 8042, doi:10.1029/2002RS002634, 2003.

Delanoë, J. and Hogan, R.: A variational scheme for retrieving ice cloud properties from combined radar, lidar and infrared radiometer, J. Geophys. Res., 113, D07204, doi:10.1029/2007JD009000, 2008.

Delanoë, J. and Hogan, R.: Combined CloudSat-CALIPSO-MODIS retrievals of the properties of ice clouds, J. Geophys. Res., 115, D00H29, doi:10.1029/2009JD012346, 2010.

Delanoë, J., Protat, A., Bouniol, D., Heymsfield, A., Bansemer, A., and Brown, P.: The Characterization of Ice Cloud Properties from Doppler Radar Measurements, J. Appl. Meteorol. Clim., 46, 1682-1698, doi:10.1175/JAM2543.1, 2007.

Donovan, D. P. and van Lammeren, A. C.: Cloud effective particle size and water content profile retrievals using combined lidar and radar observations: 1 . Theory and examples, J. Geophys. Res., 106, 27425-27448, doi:10.1029/2001JD900243, 2001.

Draine, B. T. and Flatau, P. J.: Light Scattering by Nonspherical Particles: Theory, Measurements, and Applications, chap. The Discrete Dipole Approximation for light scattering by irregular targets, edited by: Mishchenko, M. I., Hovenier, J. W., and Travis, L. D., Academic Press, San Diego, 2000.

Durden, S. L., Tanelli, S., Epp, L., Jamnejad, V., Perez, R., Prata, A., Samoska, L., Long, E., Fang, H., Esteban-Fernandez, D., and Lee, C.: A cloud and precipitation radar system concept for the ACE Mission, in: IEEE International Geoscience and Remote Sensing Society (IGRSS), Vancover, Canada, 24-29 July, 2011, Pasadena, CA: Jet Propulsion Laboratory, National Aeronautics and Space Administration, 2011.

Eliasson, S., Buehler, S. A., Milz, M., Eriksson, P., and John, V. O.: Assessing observed and modelled spatial distributions of ice water path using satellite data, Atmos. Chem. Phys., 11, 375391, doi:10.5194/acp-11-375-2011, 2011.

Ellis, S. M. and Vivekanandan, J.: Liquid water content estimates using simultaneous $\mathrm{S}$ and Ka band radar measurements, Radio Sci., 46, RS2021, doi:10.1029/2010RS004361, 2011.

Ellison, W. J.: Permittivity of Pure Water, at Standard Atmospheric Pressure, over the Frequency Range $0-25 \mathrm{THz}$ and the Temperature Range $0-100^{\circ} \mathrm{C}$, J. Phys. Chem. Ref. Data, 36, 1-18, doi:10.1063/1.2360986, 2007.

Field, P. R., Hogan, R. J., Brown, P. R. A., Illingworth, A. J., Choularton, T. W., and Cotton, R. J.: Parametrization of ice particle size distributions for mid-latitude stratiform cloud, Q. J. Roy. Meteorol. Soc., 131, 1997-2017, 2005.

Fox, N. I. and Illingworth, A. J.: The Retrieval of Stratocumulus Cloud Properties by Ground-Based Cloud Radar, J. Appl. Meteorol., 36, 485-492, doi:10.1175/15200450(1997)036<0485:TROSCP>2.0.CO;2, 1997.

Frisch, A. S., Feingold, G., Fairall, C. W., Uttal, T., and Snider, J. B.: On cloud radar and microwave radiometer measurements of stratus cloud liquid water profiles, J. Geophys. Res., 103, 2319523198, doi:10.1029/98JD01827, 1998.

Frisch, A., Shupe, M., Djalalova, I., Feingold, G., and Poellot, M.: The retrieval of stratus cloud droplet effective radius with cloud radars, J. Atmos. Ocean Tech., 19, 835-842, 2002.

Giangrande, S. E., Luke, E. P., and Kollias, P.: Automated Retrievals of Precipitation Parameters Using Non-Rayleigh Scat- 
tering at $95 \mathrm{GHz}$, J. Atmos. Ocean Tech., 27, 1490-1503, doi:10.1175/2010JTECHA1343.1, 2010.

Grecu, M. and Olson, W. S.: Precipitating Snow Retrievals from Combined Airborne Cloud Radar and Millimeter-Wave Radiometer Observations, J. Appl. Meteorol. Clim., 47, 1634-1650, doi:10.1175/2007JAMC1728.1, 2008.

Heymsfield, A. J. and Westbrook, C.: Advances in the estimation of ice particle fall speeds using laboratory and field measurements, J. Atmos. Sci., 67, 2469-2482, doi:10.1175/2010JAS3379.1, 2010.

Heymsfield, A. J., Schmitt, C., Bansemer, A., and Twohy, C. H.: Improved Representation of Ice Particle Masses Based on Observations in Natural Clouds, J. Atmos. Sci., 67, 3303-3318, doi:10.1175/2010JAS3507.1, 2010.

Hiley, M. J., Kulie, M. S., and Bennartz, R.: Uncertainty analysis for CloudSat snowfall retrievals, J. Appl. Meteorol. Clim., 50, 399-418, doi:10.1175/2010JAMC2505.1, 2011.

Hogan, R. J. and Illingworth, A. J.: The Potential of Spaceborne Dual-Wavelength Radar to Make Global Measurements of Cirrus Clouds, J. Atmos. Ocean Tech., 16, 518-531, doi:10.1175/15200426(1999)016<0518:TPOSDW>2.0.CO;2, 1999.

Hogan, R. J., Illingworth, A. J., and Sauvageot, H.: Measuring Crystal Size in Cirrus Using $35-$ and $94-\mathrm{GHz}$ Radars, J. Atmos. Ocean Tech., 17, 27-37, doi:10.1175/15200426(2000)017<0027:MCSICU>2.0.CO;2, 2000.

Hogan, R. J., Gaussiat, N., and Illingworth, A. J.: Stratocumulus Liquid Water Content from Dual-Wavelength Radar, J. Atmos. Ocean Tech., 22, 1207-1218, doi:10.1175/JTECH1768.1, 2005.

Hogan, R. J., Mittermaier, M. P., and Illingworth, A. J.: The retrieval of ice water content from radar reflectivity factor and temperature and its use in the evaluation of a mesoscale model, J. Appl. Meteorol., 45, 301-317, 2006.

Hogan, R. J., Tian, L., Brown, P. R. A., Westbrook, C. D., Heymsfield, A. J., and Eastment, J. D.: Radar Scattering from Ice Aggregates Using the Horizontally Aligned Oblate Spheroid Approximation, J. Appl. Meteorol. Clim., 51, 655-671, 2012.

Hong, G.: Radar backscattering properties of nonspherical ice crystals at $94 \mathrm{GHz}$, J. Geophys. Res., 112, D22203, doi:10.1029/2007JD008839, 2007a.

Hong, G.: Parameterization of scattering and absorption properties of nonspherical ice crystals at microwave frequencies, J. Geophys. Res., 112, D11208, doi:10.1029/2006JD008364, 2007b.

IEEE: IEEE Standard Letter Designations for Radar-Frequency Bands, Tech. rep., IEEE Aerospace and Electronic System Society, doi:10.1109/IEEESTD.2003.94224, 2003.

Illingworth, A. J., Hogan, R. J., Connor, E. J. O., Bouniol, D., Brooks, M. E., Delanoë, J., Donovan, P., Eastment, J. D., Gaussiat, N., Goddard, J. W. F., Haeffelin, M., Baltink, H. K., Krasnov, O. A., Pelon, J., Piriou, J.-M., Protat, A., Russchenberg, H. W. J., Seifert, A., Tompkins, A. M., van Zadelhoff, G.-J., Vinit, F., Willen, U., Wilson, D. R., and Wrench, C. L.: CLOUDNET: continuous evaluation of cloud profiles in seven operational models using ground-based observations, B. Am. Meteorol. Soc., 88, 883-898, doi:10.1175/BAMS-88-6-883, 2007.

Ishimoto, H.: Radar Backscattering Computations for FractalShaped Snowflakes, J. Meteorol. Soc. Jpn., 86, 459-469, 2008.

Joe, P., Kidd, C., Kollias, P., Tanelli, S., Moisseev, D., Battaglia, A., Koikinen, J., Arbery, G., Deligny, B., Caubet, E., Hudak, D., Stewart, R., Wolde, M., Im, E., Vane, D., Stephens, G., Ben- nartz, R., Blanchet, J.-P., and Cober, S.: The Polar Precipitation Measurement mission, in: Proc. 6th European Conference on Radar Meteorology and Hydrology: Satellite radar measurements and hydro-meteorological applications, Sibiu, Romania, 6-10 September, 2010.

Johnson, B. T., Petty, G. W., and Skofronick-Jackson, G.: Microwave Properties of Ice-Phase Hydrometeors for Radar and Radiometers: Sensitivity to Model Assumptions, J. Appl. Meteorol. Clim., 51, 2152-2171, doi:10.1175/JAMC-D-11-0138.1, 2012.

Kim, M.-J.: Comparisons of single scattering approximations of randomly oriented ice crystals at microwave frequencies, J. Geophys. Res., 111, doi:10.1029/2005JD006892, 2006.

Kim, M.-J., Kulie, M., Odell, C., and Bennartz, R.: Scattering of ice particles at microwave frequencies: a physically based parameterization, J. Appl. Meteorol. Clim., 46, 615-633, doi:10.1175/JAM2483.1, 2007.

Kneifel, S., Löhnert, U., Battaglia, A., Crewell, S., and Siebler, D.: Snow scattering signals in ground-based passive microwave radiometer measurements, J. Geophys. Res., 115, D16214, doi:10.1029/2010JD013856, 2010.

Kneifel, S., Kulie, M. S., and Bennartz, R.: A triple-frequency approach to retrieve microphysical snowfall parameters, J. Geophys. Res., 116, D11203, doi:10.1029/2010JD015430, 2011.

Kollias, P., Albrecht, B. A., and Marks, F.: Why Mie? Accurate Observations of Vertical Air Velocities and Raindrops Using a Cloud Radar, B. Am. Meteorol. Soc., 83, 1471-1483, doi:10.1175/BAMS-83-10-1471, 2002.

Kollias, P., Clothiaux, E. E., Miller, M. A., Albrecht, B. A., Stephens, G. L., and Ackerman, T. P.: Millimeter-Wavelength Radars: New Frontier in Atmospheric Cloud and Precipitation Research, B. Am. Meteorol. Soc., 88, 1608-1624, doi:10.1175/BAMS-88-10-1608, 2007.

Kollias, P., Rémillard, J., Luke, E., and Szyrmer, W.: Cloud radar Doppler spectra in drizzling stratiform clouds: 1. Forward modeling and remote sensing applications, J. Geophys. Res., 116, D13201, doi:10.1029/2010JD015237, 2011.

Kulie, M. S. and Bennartz, R.: Utilizing Spaceborne Radars to Retrieve Dry Snowfall, J. Appl. Meteorol. Clim., 48, 2564-2580, doi:10.1175/2009JAMC2193.1, 2009.

Kulie, M. S., Bennartz, R., Greenwald, T. J., Chen, Y., and Weng, F.: Uncertainties in Microwave Properties of Frozen Precipitation: Implications for Remote Sensing and Data Assimilation, J. Atmos. Sci., 67, 3471-3487, doi:10.1175/2010JAS3520.1, 2010.

Leinonen, J., Kneifel, S., Moisseev, D., Tyynelä, J., Tanelli, S., and Nousiainen, T.: Evidence of nonspheroidal behavior in millimeter-wavelength radar observations of snowfall, J. Geophys. Res., 117, D18205, doi:10.1029/2012JD017680, 2012.

Leinonen, J., Moisseev, D., and Nousiainen, T.: Linking snowflake microstructure to multi-frequency radar observations, J. Geophys. Res., 118, 3259-3270, doi:10.1002/jgrd.50163, 2013.

Lhermitte, R.: Attenuation and Scattering of Millimeter Wavelength Radiation by Clouds and Precipitation, J. Atmos. Ocean Tech., 7, 464-479, 1990.

Liu, G.: A database of microwave single-scattering properties for nonspherical ice particles, B. Am. Meteorol. Soc., 89, 1563 1570, 2008a. 
Liu, G.: Deriving snow cloud characteristics from CloudSat observations, J. Geophys. Res., 113, D00A09, doi:10.1029/2007JD009766, 2008b.

Löhnert, U., Crewell, S., Krasnov, O., O'Connor, E., and Russchenberg, H.: Advances in continuously profiling the thermodynamic state of the boundary layer: Integration of measurements and methods, J. Atmos. Ocean Tech., 25, 1251-1266, 2008.

Löhnert, U., Kneifel, S., Battaglia, A., Hagen, M., Hirsch, L., and Crewell, S.: A Multisensor Approach Toward a Better Understanding of Snowfall Microphysics: The TOSCA Project, B. Am. Meteorol. Soc., 92, 613-628, doi:10.1175/2010BAMS2909.1, 2011.

Lu, Y., Clothiaux, E. E., Aydin, K., Botta, G., and Verlinde, J.: Modeling variability in dendritic ice crystal backscattering cross sections at millimeter wavelengths using a modified Rayleigh-Gans theory, J. Quant. Spectrosc. Ra., 131, 95-104, doi:10.1016/j.jqst.2013.05.008, 2013.

Mace, G. G., Heymsfield, A. J., and Poellot, M.: On retrieving the microphysical properties of cirrus clouds using the moments of the millimetre-wavelength Doppler spectrum, J. Geophys. Res., 107, 4815, doi:10.1029/2001JD001308, 2002.

Mather, J. H. and Voyles, J. W.: The ARM climate research facility: a review of structure and capabilities, B. Am. Meteorol. Soc., 94, 377-392, doi:10.1175/BAMS-D-11-00218.1, 2013.

Matrosov, S. Y.: Possibilities of cirrus particle sizing from dualfrequency radar measurements, J. Geophys. Res., 98, 2067520683, doi:10.1029/93JD02335, 1993.

Matrosov, S. Y.: A Dual-Wavelength Radar Method to Measure Snowfall Rate, J. Appl. Meteorol., 37, 1510-1521, 1998.

Matrosov, S. Y.: Modeling Backscatter Properties of Snowfall at Millimeter Wavelengths, J. Atmos. Sci., 64, 1727-1736, doi:10.1175/JAS3904.1, 2007.

Matrosov, S. Y.: Feasibility of using radar differential Doppler velocity and dual-frequency ratio for sizing particles in thick ice clouds, J. Geophys. Res., 116, D17202, doi:10.1029/2011JD015857, 2011.

Matrosov, S. Y. and Battaglia, A.: Influence of multiple scattering on CloudSat measurements in snow: a model study, Geophys. Res. Lett., 36, L12806, doi:10.1029/2009GL038704, 2009.

Matrosov, S. Y., Korolev, A. V., and Heymsfield, A. J.: Profiling cloud ice mass and particle characteristic size from Doppler radar measurements, J. Atmos. Ocean Tech., 19, 1003-1018, 2002.

Matrosov, S. Y., Heymsfield, A. J., and Wang, Z.: Dual-frequency radar ratio of nonspherical atmospheric hydrometeors, Geophys. Res. Lett., 32, L13816, doi:10.1029/2005GL023210, 2005.

Matrosov, S., Shupe, M., and Djalalova, I.: Snowfall Retrievals Using Millimeter-Wavelength Cloud Radars, J. Appl. Meteorol. Clim., 47, 769-777, doi:10.1175/2007JAMC1768.1, 2008.

Mead, J. B., Mcintosh, R. E., Vandemark, D., and Swift, C. T.: Remote Sensing of Clouds and Fog with a 1.4-mm Radar, J. Atmos. Ocean Tech., 6, 1090-1097, doi:10.1175/15200426(1989)006<1090:RSOCAF>2.0.CO;2, 1989.

Mishchenko, M. I., Hovenier, J. W., and Travis, L. D. (Eds.): Light Scattering by Nonspherical Particles, Academic Press, 2000.

Mitchell, D. L.: Use of mass-and area-dimensional power laws for determining precipitation particle terminal velocities, J. Atmos. Sci., 53, 1710-1723, 1996.

Mugnai, A., Michele, S. D., Smith, E. A., Baordo, F., Bauer, P., Bizzarri, B., Joe, P., Kidd, C., Marzano, F. S., Tassa, A., Tes- tud, J., and Tripoli, G. J.: Measuring Precipitation from space: EURAINSAT and the future, chap. Snowfall measurements by the proposed European GPM Mission, edited by: Levizzani, V., Bauer, P., and Turk, F. J., Kluwer Academic Edn., 2005.

Muinonen, K., Tyynelä, J., Zubko, E., Lindqvist, H., Penttilä, A., and Videen, G.: Polarization of light backscattered by small particles, J. Quant. Spectrosc. Ra., 112, 2193-2212, doi:10.1016/j.jqsrt.2011.06.009, 2011.

Nemarich, J., Wellman, R. J., and Lacombe, J.: Backscatter and Attenuation by Falling Snow and Rain at 96, 140, and $225 \mathrm{GHz}$, IEEE T. Geosci. Remote Sens., 26, 319-329, 1988.

O'Connor, E. J., Hogan, R. J., and Illingworth, A. J.: Retrieving Stratocumulus Drizzle Parameters Using Doppler Radar and Lidar, J. Appl. Meteorol., 44, 14-27, doi:10.1175/JAM-2181.1, 2005.

Okamoto, H., Iwasaki, S., Yasui, M., Horie, H., Kuroiwa, H., and Kumagai, H.: An algorithm for retrieval of cloud microphysics using 95-GHz cloud radar and lidar, J. Geophys. Res., 108, 4226, doi:10.1029/2001JD001225, 2003.

Petty, G. W. and Huang, W.: Microwave Backscatter and Extinction by Soft Ice Spheres and Complex Snow Aggregates, J. Atmos. Sci., 67, 769-787, doi:10.1175/2009JAS3146.1, 2010.

Ray, P.: Broadband Complex Refractive Indices of Ice and Water, Appl. Optics, 11, 1836-1844, doi:10.1364/AO.11.001836, 1972.

Skofronick-Jackson, G., Kim, M.-J., Weinman, J. A., and Chang, D.-E.: A physical model to determine snowfall over land by microwave radiometry, IEEE T. Geosci Remote Sens., 42, 10471058, 2004.

Solomon, S., Qin, D., Manning, M., Chen, Z., Marquis, M., Averyt, K. B., Tignor, M., and Miller, H. L.: Climate Change 2007: The Physical Science Basis. Contribution of Working Group I to the Fourth Assessment Report of the Intergovernmental Panel on Climate Change, Tech. rep., Cambridge University Press, Cambridge, United Kingdom and New York, NY, USA, 2007.

Steer, B., Roitman, A., Horoyski, P., Hyttinen, M., Dobbs, R., and Berry, D.: Advantages of extended interaction klystron technology at millimeter and sub-millimeter frequencies, in: Proc. 16th IEEE International Pulsed Power Conference, Albuquerque, New Mexico, USA, 2007.

Stephens, G. L.: Cloud Feedbacks in the Climate System: A Critical Review, J. Climate, 18, 237-273, 2005.

Stephens, G. L., Vane, D. G., Tanelli, S., Im, E., Durden, S., Rokey, M., Reinke, D., Partain, P., Mace, G. G., Austin, R., L'Ecuyer, T., Haynes, J., Lebsock, M., Suzuki, K., Waliser, D., Wu, D., Kay, J., Gettelman, A., Wang, Z., and Marchand, R.: CloudSat mission: Performance and early science after the first year of operation, J. Geophys. Res., 113, D00A18, doi:10.1029/2008JD009982, 2008.

Stephens, G. L., L'Ecuyer, T., Forbes, R., Gettlemen, A., C.-Golaz, J., Bodas-Salcedo, A., Suzuki, K., Gabriel, P., and Haynes, J.: Dreary state of precipitation in global models, J. Geophys. Res., 115, D24211, doi:10.1029/2010JD014532, 2010.

Stevens, B. and Feingold, G.: Untangling aerosol effects on clouds and precipitation in a buffered system, Nature, 461, 607-613, doi:10.1038/nature08281, 2009.

Szyrmer, W., Tatarevic, A., and Kollias, P.: Ice clouds microphysical retrieval using 94-GHz Doppler radar observations. Part I: Basic Relations within the Retrieval Framework, J. Geophys. Res., 117, D14203, doi:10.1029/2011JD016675, 2012. 
Tanelli, S., Durden, S., Im, E., Pak, K., Reinke, D., Partain, P., Haynes, J., and Marchand, R.: CloudSat's Cloud Profiling Radar After 2 Years in Orbit: Performance, Calibration, and Processing, IEEE T. Geosci. Remote, 46, 3560-3573, 2008.

Tang, C. and Aydin, K.: Scattering from Ice Crystals at 94 and $220 \mathrm{GHz}$ Millimeter Wave Frequencies, IEEE Trans. Geosci. Remote, 33, 93-99, 1995.

Tridon, F., Battaglia, A., and Kollias, P.: Disentangling Mie and attenuation effects from spectral ratio technique, Geophys. Res. Lett., 40, 5548-5552, doi:10.1002/2013GL057454, 2013.

Tyynelä, J., Leinonen, J., Moisseev, D., and Nousiainen, T.: Radar backscattering from snowflakes: comparison of fractal, aggregate and soft-spheroid models, J. Atmos. Ocean Tech., 28, 13651372, doi:10.1175/JTECH-D-11-00004.1, 2011.

Tyynelä, J., Leinonen, J., Westbrook, C. D., Moisseev, D., and Nousiainen, T.: Applicability of the Rayleigh-Gans Approximation for Scattering by Snowakes at Microwave Frequencies in Vertical Incidence, J. Geophys. Res., 118, 1826-1839, doi:10.1002/jgrd.50167, 2013.

van Meijgaard E. and Crewell, S.: Comparison of model predicted liquid water path with ground-based measurements during CLIWA-NET, Atmos. Res., 75, 201-226, 2005.

Wallace, H. B.: Millimeter-wave propagation measurements at the Ballistic Research Laboratory, IEEE T. Geosci. Remote, 26, 253258, 1988.

Wang, Z. and Sassen, K.: Cirrus cloud microphysical property retrieval using lidar and radar measurements: I. Algorithm description and comparison with in situ data, J. Appl. Meteorol., 41, 218-229, 2002.

Wang, Z., Heymsfield, G. M., Li, L., and Heymsfield, A. J.: Retrieving optically thick ice cloud microphysical properties by using airborne dual-wavelength radar measurements, J. Geophys. Res., 110, D19201, doi:10.1029/2005JD005969, 2005.
Warren, S. G. and Brandt, R. E.: Optical constants of ice from the ultraviolet to the microwave: A revised compilation, J. Geophys. Res., 113, D14220, doi:10.1029/2007JD009744, 2008.

Westbrook, C. D., Ball, R. C., and Field, P. R.: Radar scattering by aggregate snowflakes, Q. J. Roy. Meteorol. Soc., 132, 897-914, 2006.

Westbrook, C. D., Ball, R. C., and Field, P. R.: Corrigendum: radar scattering by aggregate snowflakes, Q. J. Roy. Meteorol. Soc., 134, 457-458, doi:10.1002/qj.233, 2008.

Westbrook, C. D., Hogan, R. J., O'Connor, E. J., and Illingworth, A. J.: Estimating drizzle drop size and precipitation rate using two-colour lidar measurements, Atmos. Meas. Tech., 3, 671681, doi:10.5194/amt-3-671-2010, 2010.

Widener, K., Bharadwaj, N., and Johnson, K.: Ka-band ARM Zenith Radar (KAZR) Handbook, Technical report doe/scarm/tr-106, DOE-ARM, available at: http://www.arm.gov/ publications/tech_reports/handbooks/kazr_handbook.pdf?id=84 (last access: 28 May 2014), 2012.

Williams, J. K. and Vivekanandan, J.: Sources of Error in DualWavelength Radar Remote Sensing of Cloud Liquid Water Content, J. Atmos. Ocean Tech., 24, 1317-1336, 2007.

Wood, R.: Stratocumulus Clouds, Mon. Weather Rev., 140, 23732423, 2012.

Yang, P., Bi, L., Baum, B. A., Liou, K.-N., Kattawar, G. W., Mishchenko, M. I., and Cole, B.: Spectrally Consistent Scattering, Absorption, and Polarization Properties of Atmospheric Ice Crystals at Wavelengths from 0.2 to $100 \mu \mathrm{m}$, J. Atmos. Sci., 70, 330-347, doi:10.1175/JAS-D-12-039.1, 2013. 